\title{
Resumen:
}

Se explora el delito de extorsión en El Salvador y la manera como la mayoría de estas actividades ilícitas son planificadas, ordenadas y negociadas por grupos de crimen organizado, desde los diversos centros penitenciarios del país a través de sus estructuras reticulares. A partir de una profunda investigación bibliográfica y empírica, el trabajo se centra en analizar las condiciones criminógenas de carácter políticogubernamental, cultural-social y económico que se conjugan en El Salvador para generar que organizaciones criminales desde el interior de los centros penales se dediquen a extorsionar nacional o transnacionalmente. Finalmente se concluye que las estructuras de crimen organizado desde los centros penales constituyen una amenaza a la seguridad del Estado. Las actividades ilegales de estas organizaciones socava la habilidad del Estado para proveer servicios, proteger a las personas y mantener la confianza de la ciudadanía en el gobierno y la democracia.

El Crimen Organizado en las Cárceles: Las Extorsiones desde los

Centros Penales en

El Salvador (2008-2009)*

\section{Juan Ricardo} Gómez Hecht

Colegio de Altos Estudios Estratégicos, El Salvador ricardogomezhecht@gmail.com

Recibido: abril 24 de 2013 Aceptado: junio 10 de 2013
Palabras clave:

Extorsión, crimen organizado, prisiones, pandillas 


\begin{abstract}
:
This is an exploration of the crime of extortion in El Salvador, and the manner in which these illicit activities are planned, directed, and negotiated by organized criminal groups from inside the different penitentiary facilities around the country, and carried out through their networks. An in-depth study of the literature, matched with empirical research brings to this paper an analysis of the criminogenic conditions of a political, governmental, cultural-social, and economic nature, that come together in EI Salvador to generate criminal organizations operating from inside the correctional facilities, dedicated to extortion at the national and trans-national levels. The conclusion is that the structures of organized crime inside the penitentiary centers are a threat to the safety of the State. Illegal activities by these organizations undermine the State's ability to provide services, protect individuals, and maintain the citizens' confidence in the government and the democratic system.
\end{abstract}

\section{Key words:}

Organized Crime in the Prisons: Extorsion from the Penitentiaries in El Salvador (2008-2009)*

\section{Juan Ricardo}

Gómez Hecht

Colegio de Altos Estudios Estratégicos, El Salvador ricardogomezhecht@gmail.com

Received: April 24, 2013

Accepted: June 10, 2013

BIBLID [2225.5648 (2013), 3:1, 131.171]
Extortion, organized crime, prisons, gangs

\footnotetext{
* This paper has been expanded and worked on by the author in response to inherent editorial require. ment in the "Police and Public Security" journal.
} 
El Crimen Organizado en las Cárceles:
Las Extorsiones desde los Centros Penales en El Salvador (2008-2009)

"Según un principio consagrado por el tiempo, el nivel del progreso general o del retroceso-de cualquier sociedad nos está dado por sus prisiones"

Ángela Davis (1972, p.14)

“...si uno no cree que lo que ocurre dentro de las paredes de las prisiones no afecta a la comunidad respetuosa de la ley en el exterior, vuelva a pensarlo"1

Oficial de Policía de la Ciudad de Hayward, Ca

\section{Introducción}

La extorsión es uno de los mayores problemas que enfrenta la seguridad pública en El Salvador. Entre el año 2008 y 2009 este tipo de delito aumentó en un 172\%, llegándose a registrar la cifra de alrededor de 11 casos diarios. La mayoría de estas extorsiones $(85 \%)^{2}$ son ordenadas desde diversos centros penitenciarios, que se han constituido en bases de operaciones desde donde grupos de crimen organizado planifican, negocian y ordenan sus acciones delictivas a través de sus estructuras reticulares.

El sustancial incremento de esta actividad ilegal obedece a una serie de factores criminógenos que se conjugan y coadyuvando a generar un sistema de violencia que es alimentado al enfrentar los facinerosos pocas presiones, encontrar amplias oportunidades y elevados incentivos para participar en esta actividad ilícita.

El presente trabajo de investigación pretende profundizar en el análisis de este fenómeno, que tiene serias implicaciones para la seguridad pública nacional y regional, dada la facilidad con que el mismo se replica en otros Estados o se lleva a cabo transnacionalmente, considerándose en muchos países de la región que los sistemas penitenciarios se han convertido en verdaderas "universidades del crimen."

Los centros penitenciarios son recintos en donde los presidiarios han formado organizaciones complejas en su interior. Estas conforman prácticamente una sociedad separada con su propia cultura y dinámica. Desde hace varios años el sistema penitenciario en El Salvador ha venido sufriendo un proceso de descomposición, corrupción y deficiente control, que ha permitido que organizaciones criminales como las llamadas "maras" o "pandillas" (Mara Salvatrucha, MS y Barrio 18, M18) tomen control de los mismos. Esta situación ha generado que desde el interior de los recintos penales, las "maras" o "pandillas" extiendan sus actividades criminales dentro y fuera de las fronteras nacionales. La actividad delictiva que más impacto tiene en la población es la extorsión, dado que prácticamente cualquiera que utilice un teléfono es proclive a ser extorsionado y propenso a convertirse en víctima de estos delincuentes.

La situación descrita es sumamente preocupante debido a la amenaza que representa para el Estado salvadoreño los elevados niveles de inseguridad y criminalidad que un alto índice de extorsión genera. En el entorno económico se ahuyenta la inversión nacional y extranjera a la vez que se elevan los costos de operación de cualquier negocio; en el medio social se genera, incertidumbre, inseguridad y una gran desconfianza de la población en la capacidad del Estado

1 Benndetti. Chris. (2003), "Prison gangs reaching through bars", traducción propia. http://findarticles.com/p/articles/mi_qn4176/is_20030527/ai_n14548906/?tag=rbxcra.2.a.33.

2 Cuadro Estadistico “Incidencia Anual de Extorsiones, Años 2003-2010, proporcionado por la División de Investigación de Extorsiones Policía Nacional Civil, 03 de marzo 2010. 
para proveerles seguridad; y a nivel político es una seria amenaza al proceso democrático, ya que la población que sufre este flagelo, añora y comienza a apoyar formas autoritarias y represivas, socavando la confianza y credibilidad en los mecanismos democráticos para resolver los problemas.

Lo anterior se agrava al generarse la actividad criminal desde el interior de las cárceles, se pierde cualquier elemento intimidatorio que el Estado pueda oponer a estos criminales. La amenaza de una condena en prisión pierde su impacto disuasivo, para aquellos que consideran la cárcel "su casa" o la continuación "del barrio".

Dentro de la problemática planteada el objetivo principal de la investigación se centra en determinar y analizar las condiciones criminógenas de carácter político. gubernamental, cultural-social y económico que se conjugan en El Salvador y que generan que organizaciones criminales desde el interior de los centros penales se dediquen a extorsionar nacional o transnacionalmente a personas particulares, al sector transporte, a la industria y al comercio.

El trabajo de investigación se justifica por la complejidad y carácter multidimensional de las estructuras, eventos y procesos que configuran a las organizaciones criminales que operan desde el interior de los centros penales, y demanda que éstas sean estudiadas y analizadas desde una perspectiva sistémica que tome en cuenta sus causas, efectos y dinámicas.

En este sentido, el trabajo de investigación pretende, limitándose al estudio del delito de extorsión, realizar un análisis de: a) los actores, estructuras y dinámicas de interrelación de las organizaciones criminales que se dedican a dicha actividad ilícita; b) las condiciones criminógenas que han generado su substancial incremento a la vez que han reducido la capacidad de las autoridades para controlar sus actividades ilegales; c) las características y tipos propios de objetivación de las extorsiones en El Salvador y; d) brindar las conclusiones y reflexiones a que se ha llegado producto del análisis del objeto de estudio, que coadyuven a identificar estrategias para que el Estado pueda aumentar su efectividad y capacidad de anticipación para contrarrestar este problema.

En este orden de ideas, la investigación pretende brindar un aporte al estudio y debate de este flagelo, que se puede asegurar, sin temor a equivocación, afecta y se reproduce en la mayoría de los países de la región, dada su alta rentabilidad, bajo riesgo y la poca capacidad intimidatoria y disuasiva que disponen el o los Estados afectados.

En el Capítulo I se abordan la constitución de los Grupos de Crimen Organizado (GCO) en los centros penales, sus actores principales, sus estructuras y dinámica de interrelación. A partir del Capítulo II se estudian las condiciones criminógenas en los ámbitos político-gubernamental, cultural-social y económico que generan o fortalecen el surgimiento de GCO en las prisiones y la expansión del delito de extorsión durante los años 2003 al 2009 en El Salvador. El Capítulo III explora las diferentes formas en que los delitos de extorsión se objetivan en la sociedad salvadoreña. Finalmente, en el Capítulo IV se exponen las conclusiones y reflexiones que el trabajo de investigación ha generado y que se consideran pueden coadyuvar a superar las deficiencias y problemas detectados por cada ámbito investigado. 


\section{El Crimen Organizado en las Cárceles:

\section{Grupos de Crimen Organizado (GCO) en los Centros Penales}

Los centros penales deberían constituirse entre el delito y el regreso al derecho y a la virtud, en un "espacio entre dos mundos", un lugar para las trasformaciones individuales que restituirían al Estado los ciudadanos que éste ha perdido (Foucault, 2002). La realidad sin embargo es otra, la historia de las prisiones ha sido un catálogo de buenas intenciones y muy graves frustraciones, que han puesto en la mira del debate público el tratamiento y la idea misma de la readaptación.

El criminólogo Elías Neumann ha escrito "Quien ingresa a la prisión deja de ser hombre" (Neumann en García Ramírez, 2004 pg.568), haciendo clara referencia al proceso de deshumanización que enfrentan aquellos que ingresan a los diversos recintos penitenciarios. Este proceso deshumanizante característico de la mayoría de prisiones, se configura en la fuente desde donde emergen los GCO. Ante esta realidad no es de extrañar que los centros penales constituyan una sociedad separada, con sus propias formas de comunicación, cultura, categorías, valores y normas, totalmente indescifrables para aquellos ajenos a la misma (García Ramírez, 2004; Sousa Brandão, 2008).

El Estado y la sociedad están generalmente ausentes del "mundo de sus prisiones" y entre los "dos mundos", el de la sociedad en general y el de la sociedad de las prisiones, existe un vacío el cual es ocupado por organizaciones criminales. La cárcel, favorece y facilita la aparición de GCO, su entorno no sólo proporciona un mayor control sobre sus miembros sino que también la necesidad de supervivencia da a éstos una motivación adicional para prestar servidumbre al grupo. Asimismo, los centros penitenciarios devienen en centros de logística, reclutamiento y conducción operativa de estos grupos. Las prisiones reúnen a una población homogénea y solidaria, "una sociedad organizada de criminales" en que sus miembros se han conocido en prisión y en ella vuelven a reencontrarse (Demoscopía, 2007; Foucault, 2002).

Los recintos carcelarios se han tornado en centros de germinación de GCO, desde "el resguardo" de los cuales, sus integrantes con gran impunidad desarrollan sus actividades ilegales. Los GCO, cuya representación más patente son las pandillas, se están permeando, a través de los recintos penales, hacia todos los aspectos de la gran sociedad por medio de negocios ilícitos, el crimen organizado y la degradación social en general. Hay que tomar en cuenta el poder que dentro de los centros penales tienen las pandillas, cuando se calcula que alrededor del $45 \%$ de sus miembros se encuentran tras las rejas ${ }^{3}$. El Salvador no es ajeno a esta realidad y desde hace unos años sus prisiones han sido identificadas por las autoridades como fuentes generadoras de crimen organizado desde las cuales, cabecillas de pandillas ordenan extorsiones, secuestros, asesinatos, robo de autos y comercio de droga (El diario de Hoy, 2008). De estos ilícitos, en el que se centra la investigación es en el de las extorsiones, dado su incremento. Desde el 2003 hasta el año 2009 se tuvo un incremento en este tipo de delito de un 1,402\% (ver gráfico 1). 


\section{Gráfico 1}

Incidencia anual de extorsiones en El Salvador, 2003-2009

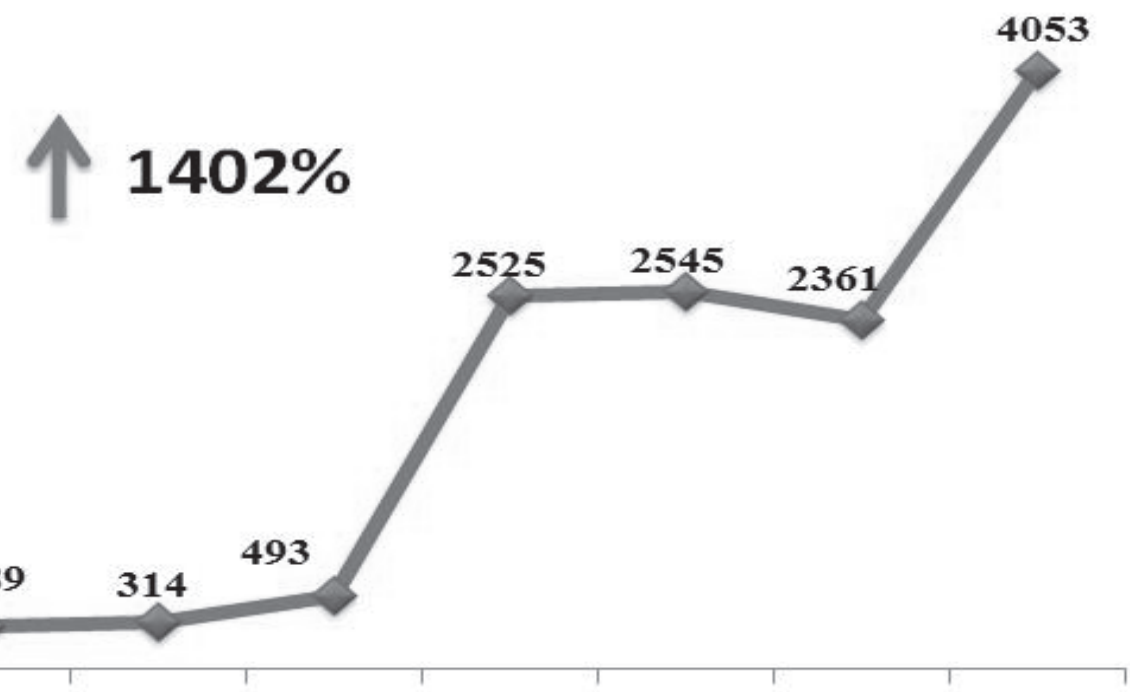

\section{$\begin{array}{lllllll}2003 & 2004 & 2005 & 2006 & 2007 & 2008 & 2009\end{array}$}

\section{Fuente: Elaboración propia con datos de la División de Investigación de Extorsiones, Policía Nacional} Civil, El Salvador

En el país, ocho de cada diez extorsiones que fueron denunciadas ante la Policía Nacional Civil, PNC, durante 2009 tuvieron su origen en el interior de una celda de alguno de los 19 centros penales del país (Membreño, 2009).

\subsection{Actores de los Grupos de Crimen Organizado (GCO) en la Cárceles}

Una multiplicidad de actores participa en la red de extorsiones desde las prisiones; desde el que planifica y dirige que se encuentra dentro del recinto, hasta el que hace la exigencia, los que brindan seguridad, quienes reciben el dinero, quienes lo entregan y quien posteriormente lo distribuye. Entre los principales actores que se relacionan en este ilícito podemos señalar:

a) Los pandilleros internos en los diversos centros penales, entre ellos se encuentran los máximos líderes de las pandillas así como los líderes dentro de cada centro penal donde la pandilla tiene presencia (Membreño, 2009). Los líderes del GCO o pandilla conforman una élite dentro del centro penal en que se encuentran; se comportan como piezas claves en los movimientos criminales y como individuos son capaces de movilizar y organizar efectivamente a sus militantes. Estos personajes actúan racionalmente en sus selecciones y acciones, pues calculan sus posibles resultados y las utilidades esperadas. Ellos hacen las reglas y hacen cumplir las normas dentro de la cárcel (Sousa Brandão, 2008). También giran órdenes y directrices a los pandilleros en libertad a efecto de que éstos a su vez realicen las respectivas coordinaciones y giren las indicaciones pertinentes a los colaboradores y familiares de los pandilleros. Entre los pandilleros internos existe 
El Crimen Organizado en las Cárceles:
Las Extorsiones desde los Centros Penales en El Salvador (2008-2009)

una distribución de funciones de acuerdo al rango o categoría que se tenga dentro de la pandilla y es desde dentro de las cárceles que éstos llevan a cabo la mayor parte de las negociaciones con las víctimas vía telefonía celular.

b) Los pandilleros libres, este grupo está conformado por aquellos que han logrado superar todos los "rituales" y demás condiciones establecidas como reglas dentro de una pandilla para pertenecer a ella. Estos individuos conocen los signos, símbolos y formas particulares de comunicación del grupo, gozan de la credibilidad del resto de miembros y son respetados en la medida en que demuestran su lealtad y fidelidad para con la pandilla, siendo la máxima prueba el llegar a asesinar en nombre o bajo las órdenes de la pandilla. El vínculo principal que une a todos los pandilleros sea que estén "internos" o "libres" es su completa identificación con la pandilla sus fines y objetivos

c) Los colaboradores, estas son personas que simpatizan con las pandillas, pero no pertenecen directamente a éstas, pues no han pasado por los "ritos" de iniciación. Su principal vinculación con la pandilla se debe al beneficio económico o de otro tipo que obtiene al apoyar a la pandilla, ya sea como vigías, en labores de encubrimiento, selección de víctimas o tareas menores de tipo logístico;

d) Los familiares, muchos familiares de los pandilleros dependen para su sustento económico del aporte que reciben de la actividad ilegal que se genera desde las cárceles. En este sentido, se involucran directamente en varias fases de la operatividad de la extorsión, actividad que se ha convertido en su "modus vivendi", en el "negocio" familiar;

e) Los Custodios, junto con los internos, constituyen los grupos más importantes en la administración penitenciaria. Una circunstancia que muchas veces se pasa por alto es que los custodios al compartir diariamente las vicisitudes, condiciones y penas de los internos, tienden a acercarse, a forjar empatía e identificarse con estos últimos. Esta circunstancia aunada a los bajos salarios que perciben los tornan vulnerables a la corrupción y;

f) Las Víctimas, prácticamente cualquier persona con posibilidades de proporcionar dinero, de la cual los pandilleros obtengan información, es una posible víctima a ser extorsionada. Asimismo existen tipos de negocios que son más propensos a ser victimizados por su alta vulnerabilidad, entre éstos se destacan tiendas, vehículos comerciales, vendedores ambulantes y sobretodo el transporte público.

\subsection{Estructura de los Grupos de Crimen Organizado (GCO) en la Cárceles}

Obviamente no existe el crimen organizado sin criminales organizados y éstos son producto de su ambiente social. El espacio cerrado de los centros penales, favorece y facilita un mayor control sobre los miembros de los GCO que pululan en su interior. Esta situación ha contribuido o a que estos grupos desarrollen estructuras más cerradas, verticales, y con un mayor nivel de cohesión social. Las prisiones definitivamente favorecen la organización o consolidación de internos en grupos criminales, solidarios entre sí, jerarquizados y dispuestos a todo tipo de complicidades futuras (Demoscopia, 2007; Von Lampe, 2003; Foucault, 2002).

Las características de estos GCO en los centros penales no son diferentes a las de otras redes criminales. Entre éstas se destacan: a) gran capacidad de adaptación y flexibilidad; b) extremada resistencia a ser desbaratadas y una significativa 
capacidad para reconstituirse, en caso de ser intervenidas; c) considerable capacidad para expandirse, inclusive transnacionalmente; d) tendencia a expandir su influencia en el "mundo superior" (en contraposición con el "bajo mundo" criminal), y reclutar a políticos burócratas, jueces y agentes de autoridad a través de la corrupción y la coerción y; e) desarrollan salvaguardas contra las infiltraciones y la provocación de daños a la organización (Williams \& Goodson, 2002).

Una característica muy propia de los GCO o pandillas en los reclusorios, es que éstas tienen una existencia propia, independientemente de los miembros que la conforman. La pandilla es el marco en el cual su membrecía fluye, frecuentemente a través de generaciones y en la cual prevalece su propio conjunto de convenciones y reglas. Entre éstas podemos contar con una estilizada y secreta historia de la pandilla, ritos de iniciación, sistema de clasificación, ritos de pasaje, reglas de conducta y rituales para honrar y despedir a los miembros muertos. La lealtad a la pandilla y sus miembros es el máximo valor del pandillero. La pandilla se torna para éste en su familia y su fuente primaria de identidad, se constituyen en comunidades emotivas que cubren una serie de necesidades afectivas de sus miembros, proporcionándoles identidades que les permiten dar sentido a sus vidas en contextos de marginación en que sus opciones de vida y de desarrollo son sumamente limitadas. Los beneficios que se obtienen de pertenecer a la organización incluyen una mezcla de consideraciones económicas como de seguridad personal: mayor credibilidad para delinquir, mayor protección, la eliminación física de rivales y el acceso a una extensa red de contactos. La capacidad articuladora y aglutinadora de estos grupos es impresionante, consiguiendo construir redes de interrelaciones y conformar fuerzas activas y organizadas que controlan un mercado criminal, que para el caso que nos atiende es el de las extorsiones. (Bailey \& Taylor, 2009; Demoscopia, 2007; Sousa Brandão, 2008; UNODC, 2007).

En El Salvador son dos las GCO que controlan desde los centros penales el ilícito de las extorsiones: la Mara Salvatrucha (MS13) y el Barrio 18. El poder que tienen estas pandillas en las cárceles puede inferirse del dato que para el año 2009 el $34 \%$ de todos los internos del sistema penitenciario eran pandilleros ${ }^{4}$.

La estructura de las pandillas es jerarquizada, dividiéndose esta prácticamente en tres niveles principales:

a) En su ápice se encuentra el liderazgo, el cual como ya se señaló están recluidos en los centros penales. Estos líderes poseen altos atributos y cualidades que les permiten liderar y comandar a los demás miembros;

b) Ios Programas para la MS o las Tribus para la M18, son sistemas de organización bajo los cuales se aglutinan varias "clicas" que operan en determinada área o zona geográfica;

c) el próximo nivel de organización lo constituyen las Clicas, que son grupos de pandilleros afiliados a una zona y/o identidad adquirida (ver Figura 1).

4 Estadísticas provistas por la Dirección General de Centros Penales, julio 2010. 
El Crimen Organizado en las Cárceles:
Las Extorsiones desde los Centros Penales en El Salvador (2008-2009)

Figura 1

Estructura de las pandillas

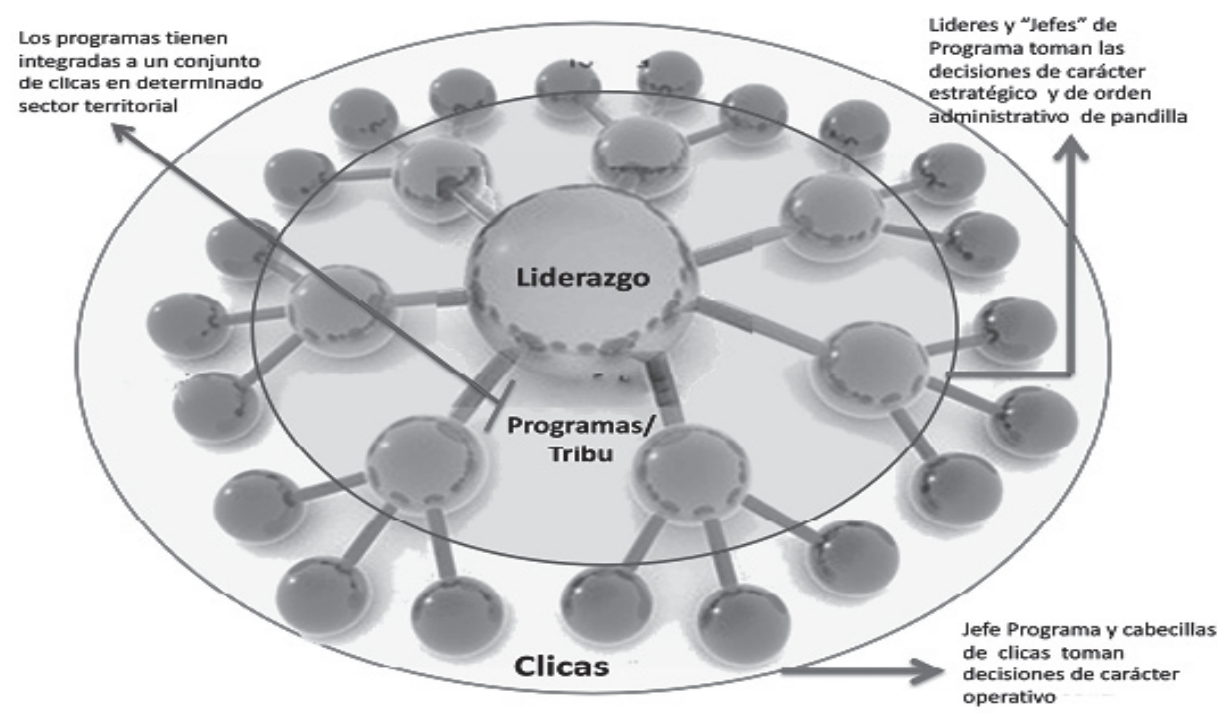

Fuente: Elaboración propia con información del Centro Antipandillas Transnacional

Los "Programas" o "Tribus" son liderados por los "Ranfleros", quienes en su mayor parte también se encuentran recluidos en prisión. Éstos controlan una determinada zona geográfica y las "clicas" que en ella se encuentran. También cada "Programa o Tribu" tiene su "Palabrero" o jefe directo.

En el proceso de toma de decisiones de las pandillas, prevalece una "democracia pandilleril" en la cual las principales decisiones que afectan a las mismas se toman con la participación de los jefes de los diferentes niveles. Entre liderazgo y los principales "Ranfleros" se lleva a cabo el principal tipo de asamblea denominado "Ranfla Mayor", donde se toman las decisiones de carácter estratégico y de orden administrativo de la pandilla. Las órdenes, directrices y decisiones que se toman en estas asambleas o que están relacionadas directamente con determinado "programa" o "tribu" son trasladadas a través de los "corredores del Programal Tribu", quienes a su vez están encargados de velar por la ejecución de éstas. El siguiente nivel de decisión se toma en las asambleas que los "Ranfleros" sostienen con los Jefes de sus clicas ("Palabrero de Clica"), denominadas "Ranfla Menor", en éstas se adoptan aquellas decisiones de tipo táctico-operativo. Estas decisiones son trasladadas a los miembros o "soldados" en la calle por los "Corredores de la Palabra" (ver Figura 2). Existe un nivel de reunión que lo constituyen los "mirin" que son las reuniones que sostienen los Jefes de las clicas con los miembros individuales que la conforman. 
Figura 2

\section{Estructura del proceso de toma de decisiones de las pandillas}

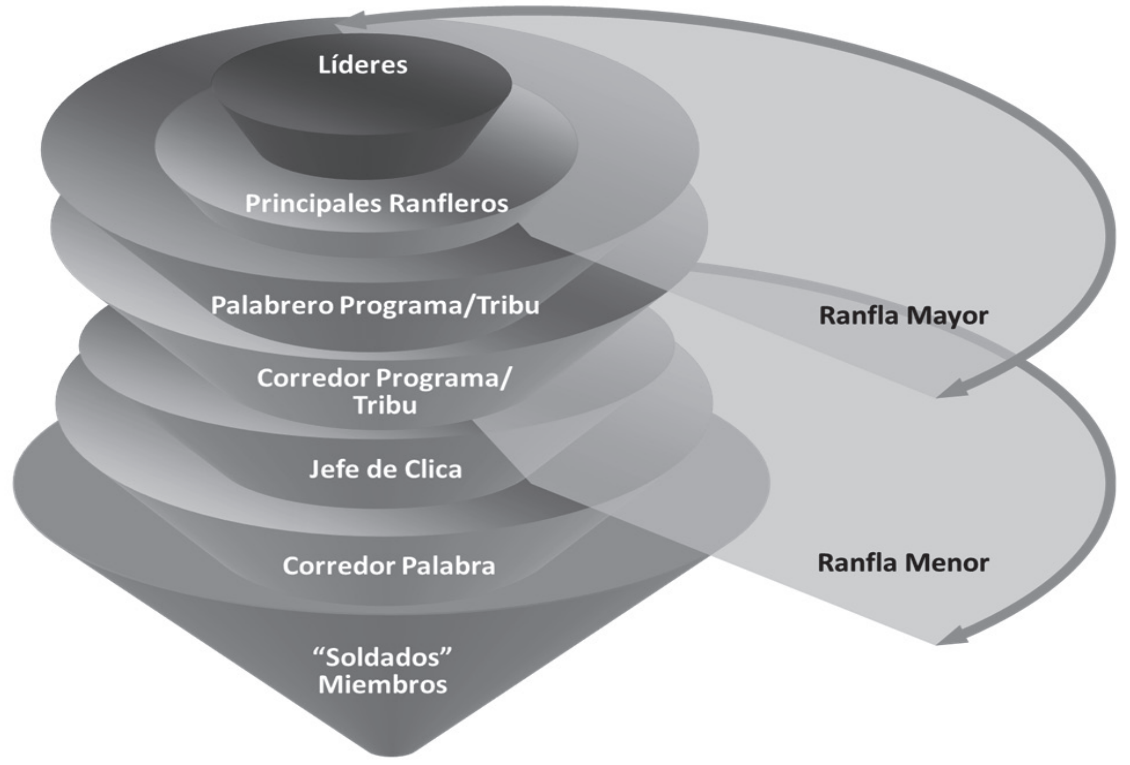

Fuente: Elaboración propia con información del Centro Antipandillas Transnacional

Es importante destacar que dentro de la estructura de las pandillas las características que denotan rango son el haber estado en la cárcel, su experiencia y las responsabilidades que ha asumido dentro de la pandilla, la provisión de inteligencia, el trato con los demás miembros, su sacrificio y empeño por mantener la seguridad de la pandilla y su territorio. También los pandilleros que vienen de los Estados Unidos de Norteamérica (EEUU) gozan de un prestigio especial al ser sujetos de consulta y planificación, referentes del origen o fundación de la pandilla y colaboran como informantes de nuevas acciones y de lo que sucede en otros países (Demoscopia, 2007).

\subsection{Dinámica de Interrelación}

Las pandillas constituyen una subcultura criminal con sus propios valores, percepciones, creencias, ritualidades y símbolos. La base de ésta radica en los mecanismos de lealtad, confianza y el establecimiento de lazos afectivos entre sus miembros. La celosa salvaguarda de su propia identidad, así como la protección de su territorio, de "su comunidad" y de su base económica son los elementos esenciales que rigen su dinámica de interrelación.

Entre los diversos niveles de las pandillas dentro y fuera de prisión, como con sus colaboradores y familiares existe una sofisticada e intricada red de comunicación. El uso del "argot" y el sistema de símbolos y signos propio de los pandilleros son utilizados para hacer las comunicaciones entre ellos, ininteligibles para aquellos fuera de la organización, así como les permite llevar a cabo sus transacciones en privado, inclusive cuando se encuentran bajo permanente vigilancia. Este sistema de comunicación propio brinda cohesión al grupo dentro de la prisión y ayuda a 

El Crimen Organizado en las Cárceles:
Las Extorsiones desde los Centros Penales en El Salvador (2008-2009)

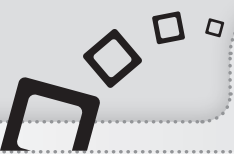

la segregación y exclusión de los otros internos. Este sistema de comunicación es el centro neurálgico de la pandilla sin el cual no sería posible su existencia. (Macaluso, 2010; Sousa Brandão, 2008).

Es a través de canales de comunicación que van desde la de tipo personal durante las visitas, la telefónica, envió de mensajes en video, en chips o micro-memorias, cartas y cualquier otra forma imaginable en que se pueda trasladar un mensaje que los líderes y "ranfleros" utilizan para comunicar sus órdenes y directrices desde los centros penales a los pandilleros en libertad, colaboradores y familiares. Asimismo, éstos establecen desde los centros penales las normas y reglas que rigen a la pandilla, así como también las sanciones a aquellos que las trasgreden. La violencia es dentro del grupo, el instrumento de control de la conducta de sus miembros.

Los pandilleros en libertad cumplen con una serie de diversas tareas desde la identificación de las potenciales víctimas a extorsionar, el brindar seguridad a la persona designada para efectuar la colecta, hasta la ejecución de la amenaza externada por el no pago de la cantidad exigida. Los colaboradores, así como también los familiares se ocupan de igual forma en la ubicación de potenciales víctimas, sirven de vigías, llevan a cabo la recolección del dinero, trasladan mensajes o introducen objetos no permitidos a los centros penales.

Utilizando la corrupción o la coerción los pandilleros internos, en el sistema penitenciario, logran adquirir la colaboración o complicidad de aquellos que han sido designados para su custodia. El involucramiento de los custodios en la dinámica de interrelación entre todos los demás actores que se ven inmersos en las redes criminales es esencial, dado que juegan un rol protagónico en el ingreso a los diversos centros penales de objetos prohibidos (teléfonos celulares, chips, memorias, mensajes, dinero, drogas, etc.), así como también asienten y facilitan la comunicación entre ellos. El soborno y la corrupción son una realidad ineludible de las prisiones, son el medio por el cual se mantiene una fluida comunicación y traslado de objetos desde y hacia los recintos penales.

Interesante resulta analizar la dinámica de relaciones entre las pandillas y los diversos agentes del Estado. En esta dinámica, las pandillas como otros GCO, coexisten con los agentes estatales en un inestable equilibrio. Las pandillas van a tender a ajustar su conducta y actividades en función de sus objetivos y recursos, la cooperación o conflicto con otras pandillas o grupos rivales, la dinámica propia de sus actividades ilícitas y la implementación de las políticas públicas. El Estado va a orientar su comportamiento de acuerdo a las cambiantes percepciones de obtención de beneficios, las amenazas a que se enfrenta, las dinámicas electorales, las expectativas de otros Estados y las estrategias adoptadas por los GCO. En la medida que los gobiernos tienden a controlar o reprimir las actividades criminales de las pandillas, éstas utilizarán varias medidas, dependiendo de la situación, que van desde la evasión, la corrupción, hasta la confrontación abierta con las autoridades. La regla general es que en la medida de lo posible las pandillas como cualquier otro GCO van a evitar la confrontación. Ésta siempre resulta costosa y tiende a perturbar sus negocios ilícitos. El Estado, por su parte va a ejercer su control sobre la actividad criminal en la medida que esté afectando la seguridad y el orden, utilizando tácticas de coexistencia, de disrupción o de eliminación (Bailey \& Taylor, 2009). 


\section{Condiciones Criminógenas que Fomentan el Fenómeno}

Las condiciones criminógenas son definidas como desacoplamientos estructurales incongruencias e inequidades en las esferas de la política, la cultura, la economía y la ley, que generan o fortalecen la demanda de bienes y servicios ilegales, producen incentivos para que ciertos actores participen en las transacciones ilícitas y reducen la capacidad de las autoridades para controlar este tipo de actividades (Passas, 2000). Estas condiciones se categorizan en político/gubernamentales, cultural/sociales o económicas. A continuación se exponen aquellas condiciones criminógenas que más inciden en la generación de las extorsiones desde los centros penales en El Salvador, por cada una de estas categorías.

\subsection{Condiciones Criminógenas de Carácter Político-Gubernamental}

Existen en El Salvador problemas endémicos que están relacionadas con temas de gobernabilidad y de decisión política que inciden en la capacidad estatal para dar respuesta al problema objeto de estudio: la baja capacidad para satisfacer las crecientes demandas populares, el deterioro o estancamiento de algunas instituciones democráticas, la corrupción, la urbanización desordenada, el deficiente control de armas y su extensa proliferación, la errónea y prevaleciente percepción de los Derechos Humanos como derechos que asisten al delincuente, una legislación inadecuada, un lento e ineficiente sistema judicial y la fragmentación de los partidos políticos. Todos estos factores facilitan el surgimiento del problema, sin embargo, las principales condiciones criminógenas que están generando que el fenómeno se reproduzca son: la deficiente seguridad y control penitenciario, la baja capacidad coercitiva y de provisión de seguridad por parte del Estado y la implementación en el pasado de planes represivos orientados a la detención indiscriminada de sospechosos y el continuo flujo de las deportaciones masivas.

\subsubsection{Deficiente Seguridad y Control Penitenciario}

[El]...sistema penal que es el reflejo de lo que somos... es una especie de civitas diavoli elaborada y administrada por el hombre con la esperanza de gobernarla. Pero a veces - lo sabemos perfectamente- el sistema opera por su cuenta y el aprendiz de brujo se convierte en una de sus primeras víctimas... (García Ramírez, 2004, p.550)

Esta observación tiene una gran vigencia al describir la situación de muchas de las cárceles latinoamericanas, sin exceptuar las de EI Salvador. La deficiente seguridad y control penitenciario se refleja en los siguientes datos: para agosto de 2009 se encontraban tras las rejas 3,567, internos extorsionistas y 1,300 extorsiones habían sido ordenadas desde el interior de un penal (La Prensa Gráfica, 2009).

En el país el sistema penitenciario está conformado por 19 recintos, 2 centros abiertos y 2 pabellones hospitalarios. Todo el sistema está administrado por la Dirección General de Centros Penales, que a su vez depende del Ministerio de Justicia y Seguridad Pública. Los problemas de seguridad y control penitenciario comienzan desde su concepción: de acuerdo al funcionario de la mencionada Dirección entrevistado, ninguno de estos centros penales fue diseñado para tal fin, "...inclusive recibimos como centro penal un ex beneficio de café..."

5 Entrevista realizada por el autor a funcionario de la Dirección General de Centros Penales. julio 2010. 

El Crimen Organizado en las Cárceles:
Las Extorsiones desde los Centros Penales en El Salvador (2008-2009)

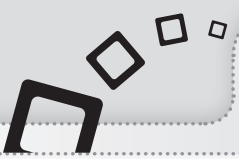

El severo hacinamiento, la ausencia de programas efectivos de rehabilitación, el mantenimiento de personas en estado de detención preventiva con criminales convictos y de condiciones carcelarias indignas, aunado a la incapacidad del Estado de garantizar la seguridad y derechos de los internos son algunos de los graves problemas que aquejan el sistema. En las prisiones generalmente se brinda prioridad a la seguridad, en detrimento de otros aspectos relacionados con el tratamiento, la salud y la administración. A todos estos problemas hay que sumarle que en su mayor parte los sistemas penitenciarios no disponen de presupuestos adecuados para cumplir con su función. En El Salvador, no obstante el marcado aumento de la población reclusa, el presupuesto sólo se vio incrementado en el período 2005-2007 en un 30\%, en tanto que el personal responsable de la custodia, tratamiento y administración de los centros se disminuyó en un $8.1 \%$ en el mismo período (Dammert y Zuñiga, 2008; Gutiérrez, 2008).

El uso generalizado de la prisión como pena y como medida cautelar, tornando la libertad una excepción a la norma, ha sido uno de los factores que han contribuido al hacinamiento existente en las prisiones en el país.

El hacinamiento ha propiciado situaciones dramáticas en los centros de reclusión, condiciones inhumanas y de insalubridad; baños que son usados como dormitorios, socavones estrechos y sin ventilación donde duerme un gran número de reclusos, utilización del suelo como catre, entre muchas circunstancias. Estos escenarios conllevan inevitablemente a la vulneración de distintos derechos de los reclusos tales como el derecho a la vida, a la dignidad, a no sufrir tratos ni penas crueles humanas o degradantes, entre otros (FESPAD. 2007, p.3).

La población de internos en El Salvador se ha casi cuadruplicado en los últimos ocho años (2002 a julio 2010) de 6,000 a 23,800. En algunos centros penales como el de Ciudad Barrios y el de Chalatenango, la población interna sobrepasa en un $256 \%$ y en un $433 \%$, respectivamente, la capacidad para la cual dichos centros fueron diseñados. El descontrol que estas condiciones generan se refleja en los cada vez mayores decomisos de aguardiente "chicha" que se realizan en las cárceles. Entre el año 2006 al 2009 estos se han incrementado de 765.5 litros a 10,657.57 litros (Ver Gráfico 2). 


\section{Gráfico 2}

\section{Cantidad de internos en Centro Penales. Año y decomisos de chicha (en litros), 2004-2009}

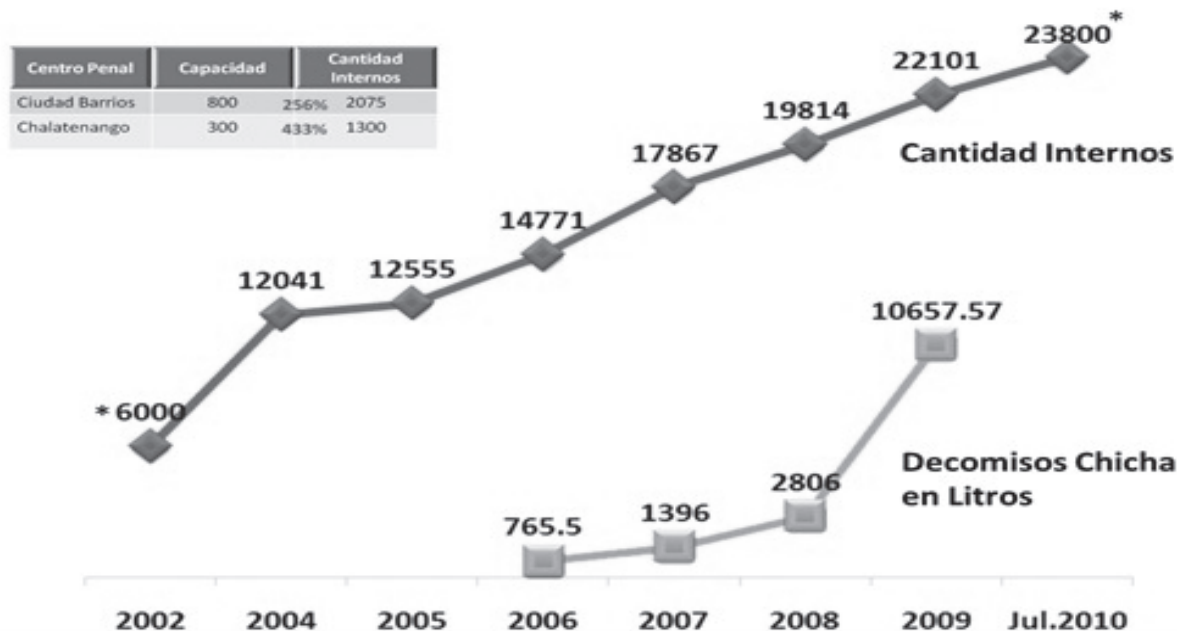

Fuente: Elaboración propia con datos provistos por la Dirección General de Centros Penales.

Nota: La cantidad de internos para el año 2006 se tomó de Hume, en Jütersonke et. al, (2009), p. 382. La cantidad de internos "julio 2010" se obtuvo de La Prensa Gráfica, 13 de julio de 2010.

Estas tremendas condiciones de hacinamiento aunadas a la inadecuada infraestructura de la mayoría de las instalaciones, no solo afectan las funciones básicas del sistema penitenciario sino que van aparejadas de otros males carcelarios como lo son la desgracia cualitativa y la deficiente calidad de vida de sus internos. La complejidad del problema del hacinamiento se expresa en la prolongada detención preventiva de los internos, la insalubridad, la escasa promoción de medidas alternativas a la privación de libertad, la falta de capacitación de los funcionarios encargados de su custodia y en la insuficiencia de los programas de rehabilitación y reinserción social. La sobrepoblación carcelaria pone en riesgo la seguridad, tanto de los internos como de sus custodios, facilita el cometimiento de abusos y dificulta la vigilancia. También promueve la generación de un ámbito de degradación de derechos, de corrupción en su administración y el desarrollo de GCO (Dammert y Zuñiga, 2008; García Ramírez, 2004).

Otro factor que incide en la deficiente seguridad y control penitenciario es que algunos de los centros penales están practicamente bajo el control de las pandillas. El sistema penitenciario albergaba en el año 2009 a 7,555 pandilleros que permanecían internos en seis cárceles o centros penales del país, (Zacatecoluca, Ciudad Barrios, Chalatenango, Cojutepeque, Quezaltepeque e Izalco) desde donde se generan el $85 \%$ de las extorsiones. Entre los centros penales problemáticos, se destaca el de Ciudad Barrios el cual alberga 1,860 pandilleros de la MS y se calcula que desde su interior se gesta el 53\% de este tipo de ilícito (ver Figura 3). 


\section{El Crimen Organizado en las Cárceles: \\ Figura 3 \\ Los Centros Penitenciarios que albergan pandilleros; la pertenencia y cantidad de los mismos}

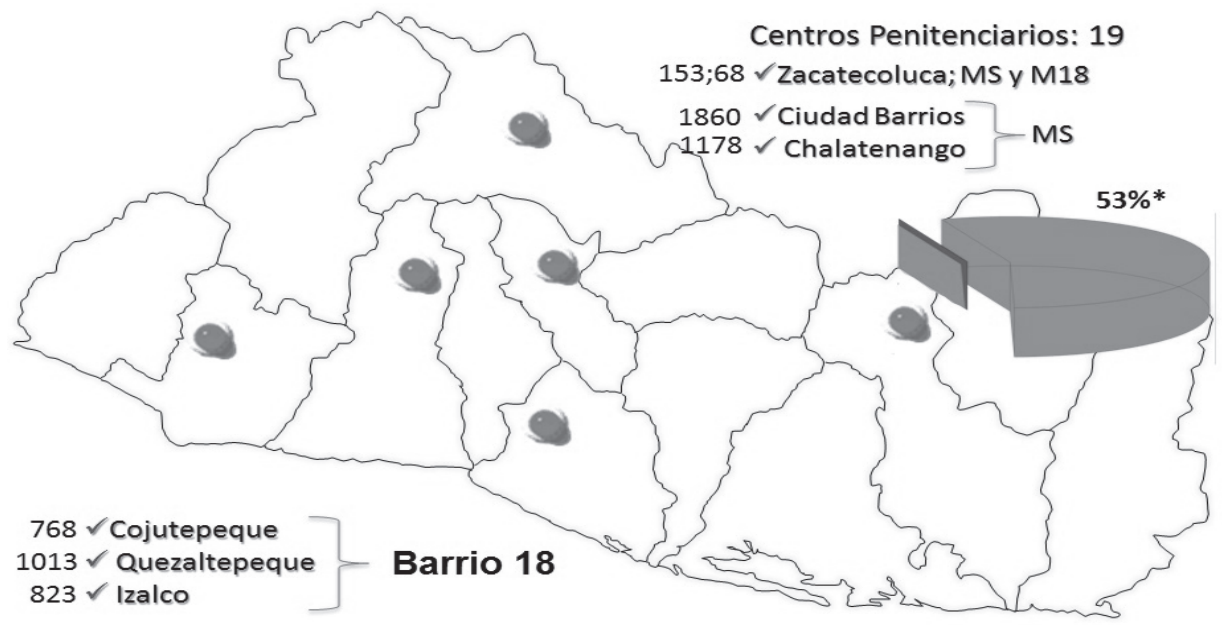

Fuente: Dirección General de Centros Penales

*División de Investigación de Extorsiones

Esta concentración de pandilleros les permite obtener fácilmente el dominio y control del resto de internos y por ende de la prisión misma. Al momento que la administración penitenciaria no pueda asegurar que los centros penales sean seguros y ordenados, este vacío será rápidamente llenado por las pandillas, quienes dictarán sus propias normas y reglas dentro del recinto.

Dentro del sistema penitenciario el contrabando es poder (Danitz, 1988) y como se ha señalado un elemento esencial para permitir que este fenómeno se repoduzca dentro de las cárceles lo constituyen los funcionarios de seguridad o "custodios". Evidentemente a mayor cantidad de estos funcionarios y más rigurososos procedimientos de seguridad se tiende a prevenir el contrabando y la violencia dentro de los penales (Gaes y otros, 2001). En El Salvador para el año 2007 se reportaban 840 "custodios" en la Dirección de Centros Penales (Cámara de Comercio, 2010) muy por debajo de los 1,800 requeridos actualmente de acuerdo a las autoridades penitenciarias, para garantizar la seguridad y el orden en los penales. Además los bajos salarios de estos funcionarios, sumados a su escasa formación especializada los torna altamente vulnerables a caer en la corrupción. Alrededor de 70 "custodios" han sido depurados por sospechas de corrupción, también se han depurado, por razones similares, a personal de los consejos criminológicos, y hasta directores de cárceles (La Prensa Gráfica, 2010b). El nivel de contrabando en las prisiones es alto, entre enero de 2009 y el 9 de abril de 2010 un total de 447 personas han sido detenidas por introducir celulares, chips, cargadores, drogas y hasta armas de fuego al sistema penitenciario (El Diario de Hoy, 2010b).

Uno de los principales factores que facilitan la generación de GCO en los centros penales es la falta de separación entre los internos, circunstancia que posibilita un tipo de "contaminación criminal" donde los internos con menos experiencia 
aprenden de los más avanzados. Igualmente al facilitar contactos entre pandilleros y aquellos que no lo son y al permitir la relación entre pandilleros de distintas "clicas" refuerzan la cohesión social de estos GCO obligados a sobrevivir en el entorno hostil de las cárceles. (Dammert y Zuñiga, 2008; Demoscopia, 2007). Es importante entender que bajo estos "vicios", más prisiones no van a disminuir la criminalidad sino por el contrario, ésta va a tender a incrementarse.

Después de haber salido de prisión se tienen más probabilidades de regresar a ella. Los centros penales se configuran en "fábricas" de delincuentes y criminales, debido al tipo de existencia que hace llevar a los internos. Idealmente las prisiones debieran aplicar las leyes y enseñar a respetarlas sin embargo todo su funcionamiento se desarrolla sobre el abuso de poder.

\begin{abstract}
"El sentimiento de la injusticia que un preso experimenta es una de las causas que más pueden hacer indomable su carácter. Cuando se ve así expuesto a sufrimientos que la ley no ha ordenado ni aun previsto, cae en un estado habitual de cólera contra todo lo que lo rodea; no ve sino verdugos en todos los agentes de la autoridad; no cree ya haber sido culpable: acusa a la propia justicia. (Foucault, 2002)".
\end{abstract}

\title{
2.1.2. Baja capacidad coercitiva y de provisión de seguridad por parte del Estado
}

La capacidad del Estado es un concepto de dos facetas: a) la habilidad del Estado para garantizar el respeto a la ley, la seguridad y el orden público y b) su efectividad en términos de la eficacia en sus funciones distributivas. En este sentido, la baja capacidad de los Estados se mide en términos de sus funciones coercitivas y distributivas. La capacidad coercitiva se mide contra la habilidad del Estado de hacer cumplir la ley. El porcentaje de criminales que gozan de impunidad es un indicador representativo de la medida de eficiencia en el mantenimiento de la seguridad y orden público. Este indicador se complementa con un análisis del sistema judicial y la tasa de agentes de policía/habitante. La función distributiva de un Estado se mide por el nivel de la inversión social, incluyendo reducción de la pobreza, educación y servicios de salud. Las capacidades en estas dos áreas son fundamentales para alcanzar la gobernabilidad (Richani, 2007). En este apartado se abordará lo relativo a la baja capacidad coercitiva del Estado, dejando para el apartado 2.2.3 lo relativo a su capacidad distributiva.

La obligación básica del Estado es la de asegurar la seguridad de su ciudadanía. Cuando el estado falla en satisfacer esta función esencial muchos ciudadanos cesarán de tomar la democracia seriamente. El fracaso en proveer seguridad por parte del Estado es particularmente peligroso en las jóvenes democracias. Las personas con frecuencia interpretan que elevados índices de crimen evidencian que las protecciones constitucionales han sido demasiado extendidas. La percepción de desorden puede provocar nostalgia por el retorno de regímenes autoritarios. La percepción que el crimen se encuentra fuera de control a menudo conlleva a la apreciación de que la policía es incompetente con lo que se mina la confianza pública en el gobierno como un todo. Lo que es peor aún es que en un ámbito desprovisto de protección policial, las personas recurrirán a un "patrón" o "capo" por ayuda o inevitablemente van a buscar la asistencia de los GCO o o de las mismas pandillas.

En un país donde reina el crimen y la corrupción, se pervierte a la economía, el Estado no tiene más el monopolio del uso de la fuerza y sus ciudadanos no confían más en sus líderes e instituciones públicas. Por ese motivo, el contrato social se hace 

El Crimen Organizado en las Cárceles:
Las Extorsiones desde los Centros Penales en El Salvador (2008-2009)

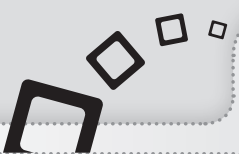

jirones y la gente toma la ley en sus propias manos ya sea para defenderse o cometer ofensas. Igual problema presenta el sistema judicial, meses de trabajo de la policía se pueden borrar, cuando las cortes fallan en administrar justicia. La efectividad de los tribunales es seriamente impedida cuando los fiscales y jueces pueden ser intimidados por el crimen organizado (Mehlum, et. al., 2002; UNODC, 2007).

El alto nivel de impunidad en El Salvador se hace patente en cifras como las siguientes: solo el 4\% de los homicidios cometidos son resueltos (El Diario de Hoy, 2010c), eso a pesar que en entre los años 2005 al 2009 se han contabilizado 18,771 homicidios ${ }^{6}$ y se alcanzó una tasa de los mismos de 72 por cada cien mil habitantes (El Faro, 2009). Este alto nivel de impunidad se apareja a otro elemento importante que exacerba el crimen, el hecho de que la prisión deja de ser un elemento disuasivo. Muchos de los pandilleros entrevistados en un estudio manifestaron encontrar la vida fuera de la cárcel más difícil que la vida dentro de ella (Richani, 2007).

Al no existir una provisión de niveles aceptables de seguridad por parte del Estado se desencadenan dos fenómenos: la proliferación de armas entre la población y la multiplicación de los servicios privados de seguridad. En El Salvador se estima que hay actualmente 450,000 armas pequeñas y livianas, suficientes para que uno de cada cuatro habitantes ande armado. Asimismo más del $60 \%$ de éstas en circulación son ilegales. Frente a estos datos no es de extrañar que más del $76 \%$ de todos los homicidios en el país se cometan con armas de fuego (FLACSO, 2006; UNODC, 2007). En lo concerniente a los servicios privados de seguridad, su incremento propicia: a) la inequidad en la distribución de la seguridad, en la cual las comunidades afluentes son patrulladas preventivamente por los miembros de los agencias de seguridad privada y la policía y las comunidades pobres son patrulladas represivamente por la policía; b) la seguridad deviene en una mercancía la cual responde al mercado y no a los intereses más elevados de la sociedad y; c) las agencias de seguridad privada se convierten en verdaderos ejércitos privados, los cuales en la mayoría de casos supera en efectivos a las policías de la región. Últimamente en el país han estado proliferando los servicios de seguridad ilegales o de protección, algunos de los cuales son provistos por los mismos pandilleros.

\subsubsection{Implementación de Planes Represivos orientados a la Detención Indiscriminada de Sospechosos y Deportaciones Masivas.}

Entre los objetivos de seguridad pública de cualquier nación están el mantener el orden, la tranquilidad y la integridad física y de los bienes de todas las personas dentro del territorio nacional. Estos objetivos son de difícil cumplimiento cuando los GCO atentan contra el monopolio estatal del uso de la fuerza y ejercen el suficiente control territorial para exigir el pago de extorsiones. Un gobierno que no dé pronta respuesta a esta problemática rápidamente comienza a perder la confianza de sus gobernados con la consiguiente merma de legitimidad. Frente a esta situación, desafortunadamente las medidas que se han implementado inmediatamente son el "endurecimiento" de las leyes y de planes represivos, las cuales al final resultan contraproducentes. Las primeras porque al no ser producto de una planificación estratégica, sino más bien de reacciones al problema, terminan complicando más un ya abarrotado marco legal y afectan la integralidad que debieran mantener con la constitución y la legislación secundaria. Las últimas porque no sólo desgastan a las

6 http://noticias.terra.es/2010/mundo/0102/actualidad/el-salvador-registro-4365-homicidios-en2009-la-cifra-mas-alta-en-diez-anos.aspx 
autoridades realizando detenciones masivas para poner al poco tiempo en libertad a los detenidos sino también al ser una medida de tipo confrontativo que genera una reacción de confrontación de aquellos a quienes va dirigida sino que aumenta su alienación. También hay que tener en cuenta que las pandillas, dado su grado de institucionalización son prácticamente invulnerables a la represión. No sólo son actores protagónicos dentro de la comunidades que controlan sino todo su accionar gira en el mantenimiento y preservación de su organización (Hagedorn, 2008).

Ante la amenaza que representaban las pandillas y el clamor de acción por parte de la ciudadanía el gobierno de El Salvador optó por adoptar como política de seguridad la implementación durante los años 2003 y 2004 de los Planes Mano Dura y Súper Mano Dura, cuya finalidad era el desmantelar dichos GCO por medio de detenciones masivas de sus integrantes. Producto de la ejecución de estos planes fue la detención de miles de pandilleros. Entre el 23 de julio de 2003 al 05 de junio de 2004 se detuvieron en las Regiones Central y Metropolitana a 16,132 pandilleros $^{7}$. De éstas detenciones 13,551 se resolvieron en los tribunales con sobreseimiento definitivo (84\%), 1,129 (7\%) con sobreseimiento provisional, 807 (5\%) con instrucción con detención y 645 (4\%) estaban pendiente de audiencia a fecha 05 de junio de 2004.

Estos planes que en un inicio se percibieron como un éxito tanto por la ciudadanía como por las autoridades y con los cuales se logró fichar a la mayoría de los pandilleros, tuvo al final una serie de efectos contraproducentes. En primer lugar, propició una recomposición de la estructura, organización interna, sistema de normas y valores, fines y objetivos de las pandillas. En este sentido, éstas se tornaron en organizaciones más complejas y profesionales, transformando su imagen y adoptando nuevas formas de identificación, a manera de dificultar su captura y garantizar una mayor clandestinidad en su accionar. Ante la persecución estatal implacable, las pandillas tuvieron que abandonar sus territorios tradicionales, lo que aumentó su movilidad e introducción en nuevos espacios, a la vez que se fortaleció su cohesión interna, solidaridad y unidad grupal. También ante la amenaza gubernamental, se tornaron más sofisticadas en su operatividad, utilizando vehículos, medios de comunicación y armas de fabricación industrial, algunas inclusive de uso privativo de las fuerzas armadas.

En segundo lugar, las detenciones masivas y el despliegue por parte de la Policía Nacional Civil de unidades especializadas ${ }^{8}$ contra las diferentes modalidades de delito y las mismas pandillas, saturaron los centros penales. Entre los años de 2004 al 2009 se incrementó la presencia de pandilleros en el sistema penitenciario de 2,963 a 7,555 (Ver Gráfico 3). Ante los problemas que éstos ocasionaban y el peligro que representaban para el resto de reos comunes, se optó por la segregación de los internos en función de su pertenencia a determinada pandilla, situación que generó que su liderazgo se estructurará a nivel nacional, se cohesionará y consolidará la identidad de estos GCO, a la vez que se fortalecieron sus lazos de lealtad y compromiso y se tomaran las pandillas prácticamente el control de las prisiones (Aguilar Villamariona, 2008).

7 Fuente: PNC, 2004. Informe Comparativo de Actividad Plan Mano Dura Regiones Metropolitana y Central De éstos 8,906 pertenecían a la MS, 6,519 al Barrio 18, 126 Mao Mao, 58 La Máquina y 523 a otras pandillas.

8 Algunas de las unidades especializadas desplegadas fueron: la División de Investigación de Homicidios, la Fuerza de Tarea Antiextorsiones (hoy División de Investigación de Extorsiones), Centro Antipandi. Ilas Transnacional y Grupo de Operaciones Especiales. 


\section{Gráfico 3}

Pandilleros internos por año, 2004-2009

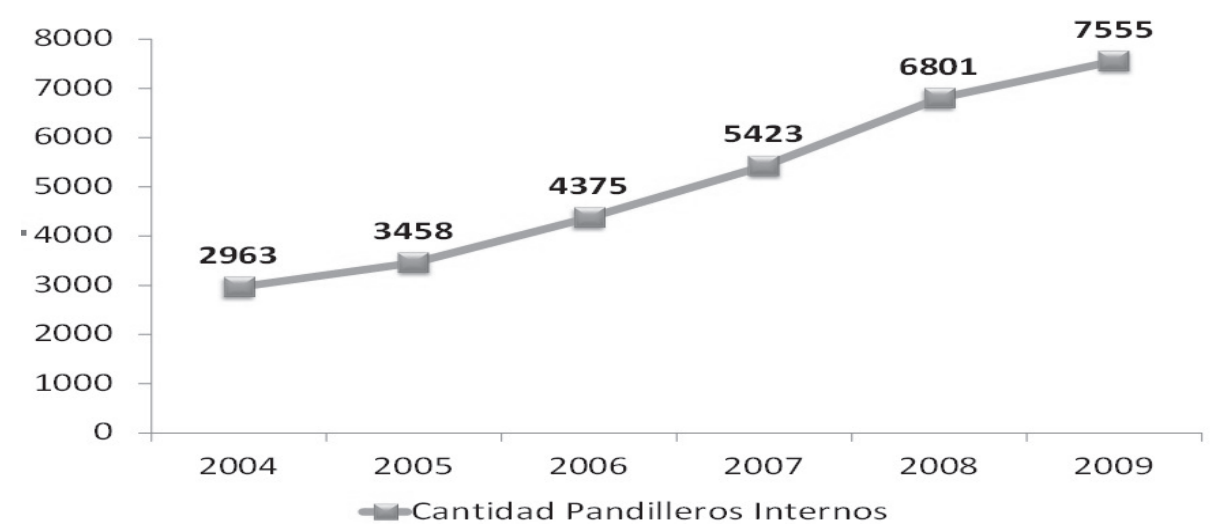

Fuente: Elaboración propia con información de la Dirección General de Centros Penales

Otro factor que ha contribuido a desencadenar la existencia de GCO en los centros penales son las deportaciones masivas desde los EEUU. Entre los años de 2003 y 2009 se han recibido en El Salvador 102,875 personas indocumentadas y 17,454 personas con antecedentes criminales (Ver Gráfico 4).

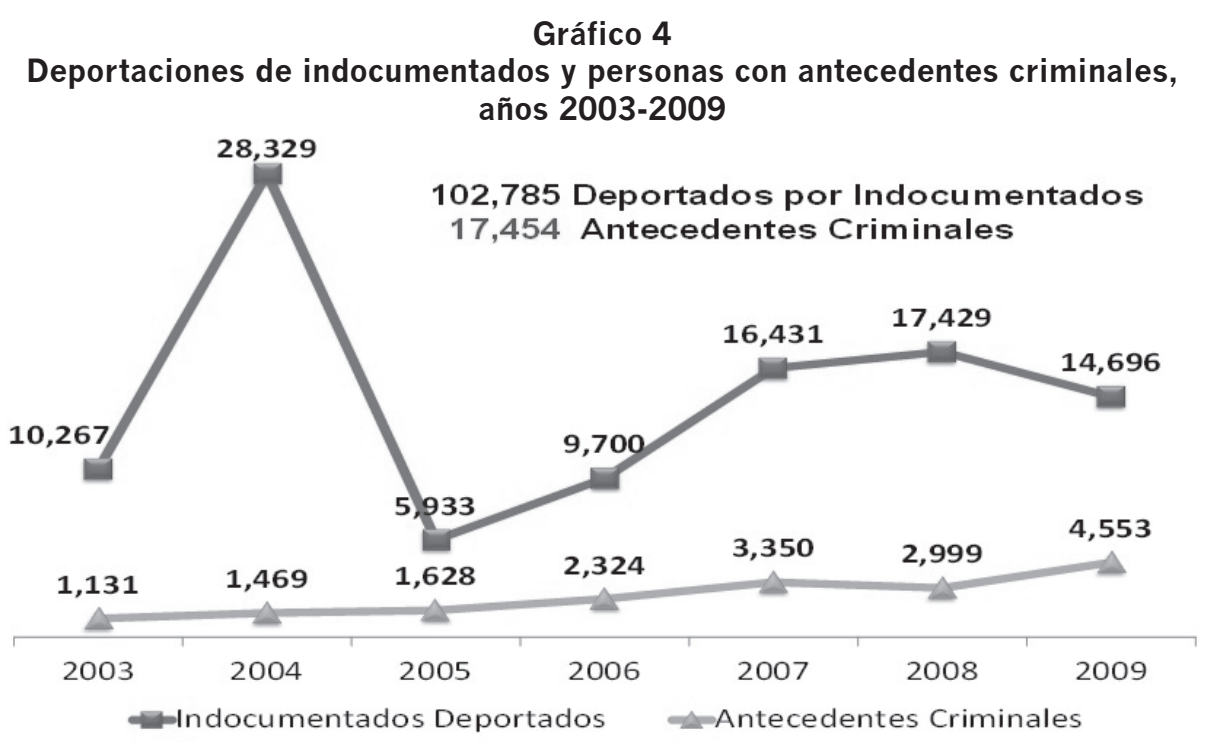

Fuente: Elaboración propia con datos de la División de Fronteras de la Policía Nacional Civil

Estas deportaciones no sólo han venido a sobrecargar el ya frágil soporte social estatal, sino también ha posibilitado el intercambio de experiencias entre aquellos que han vivenciado la cultura pandilleril y la vida en los centros penales de los EEUU. Esta situación ha propiciado a su vez la transnacionalización de las pandillas y la importación de nuevas formas de organización y de operación más sofisticadas, así 
como también ha favorecido el contacto con otras organizaciones criminales de mayor peso que las pandillas y dedicadas a actividades ilícitas más rentables que la extorsión. Además ha generado un círculo vicioso en que muchos de los criminales deportados, luego de su estadía en EI Salvador regresan ilegalmente a los EEUU, extendiendo sus actividades y cultura en el área geográfica por la cual transitan en su trayecto.

\subsection{Condiciones Criminógenas de Carácter Cultural-Social}

El Salvador ha sufrido varios cambios de carácter social y cultural que han propiciado la aparición de GCO. Entre los primeros se destaca el paso de una sociedad rural a una sociedad urbanizada y los bajos niveles de control social ${ }^{9}$. Entre los últimos sobresale la conformación en el país de un sistema de violencia.

El país ha estado en un continuo proceso de urbanización. En 1980 la población urbana constituía un 40\% de la población total, para 1990 era el 47\% y en el año 2007 se constituía en el segmento mayoritario, al alcanzar el $62.7 \%$ (Dirección General de Estadísticas y Censos, 2008; PNUD, 2003). Este proceso de urbanización ha ido acompañado de una población "flotante" que se concentra en los márgenes de las grandes ciudades y pertenecen a las escalas económicamente más vulnerables de la sociedad. Estas comunidades viven en una situación precaria, plagada de una severa penuria, violencia, alcohol, drogas, prostitución y promiscuidad. Circunstancias que los tornan en fácil presa de los GCO que los utilizan como colaboradores o perpetradores para cometer sus fechorías y sus comunidades se convierten en lugares idóneos para buscar refugio. Una estadística resulta reveladora sobre el efecto de las ciudades en el crimen, un hogar en una ciudad de más de 1 millón de habitantes tiene el doble de probabilidad de ser victimizado que un hogar en una ciudad con menos de 20,000 habitantes (Brennan-Galvin, 2002; Cuadra, 2003).

Agravando el problema de la urbanización, la sociedad salvadoreña desde finales del siglo pasado ha venido presentando bajos niveles de control social, los cuales se expresan en redes sociales débiles y de baja calidad, poca cohesión social intra y entre las comunidades, poca participación comunitaria, altos niveles de desintegración familiar y elevados niveles de "estrés" socio económico. Además en el país, la violencia se ha enquistado; su constante exposición en la comunidad tiende a tornarla en una manera legítima para la resolución de conflictos, sobre todo cuando se perciben que los mecanismos estatales son incompetentes, corruptos o prejuiciados. A pesar de lo expuesto tres condiciones criminógenas se destacan en este ámbito: la prevalencia de una elevada percepción de inseguridad, la amplificación de dicho fenómeno por parte de los medios de comunicación social y la compensación del débil o nulo soporte social estatal y déficits de gobernabilidad por parte de los GCO.

\subsubsection{Elevada Percepción de Inseguridad}

La elevada percepción de inseguridad es una de las características que más destaca en la actual sociedad salvadoreña. La misma es producto directo del incremento de la criminalidad y delincuencia, así como del descontento, desconfianza y violencia presentes en el colectivo social. La inseguridad transforma las relaciones fundamentales de poder, afecta las economías de mercado, la legitimidad de las instituciones políticas y las bases del orden social y la sicología de la vida cotidiana de las personas (Davis, 2006). La inseguridad deviene en un elemento

9 El control social entendido como el conjunto de prácticas, actitudes y valores destinados a man. tener el orden establecido en las sociedades (Jary \& Jary, 1991). 

El Crimen Organizado en las Cárceles:
Las Extorsiones desde los Centros Penales en El Salvador (2008-2009)

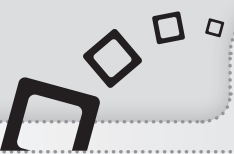

subjetivo que se refleja en un temor generalizado por ser víctima de algún tipo de delito o de cualquier otro acto de violencia dada las condiciones generalizadas del entorno en que se habita. Muchas veces esta percepción suele ser superior a la verdadera situación del crimen o delincuencia en determinada sociedad. Esta situación empeora si la población pierde la confianza en las instituciones estatales que deben velar por su seguridad y bienestar.

La inseguridad ha generado también dentro de los ámbitos urbanos el surgimiento de una "arquitectura de miedo", al buscar las personas refugio bajo comunidades y casas amuralladas, situación que ha fragmentado el espacio público, engendrando nuevas formas de segregación espacial e discriminación social (Jütersonke, Muggah \& Rodgers, 2009).

El que existan en El Salvador elevados niveles de inseguridad facilita la labor de los extorsionistas, dado que la mayoría de las personas están conscientes de su vulnerabilidad (real o percibida), de que fácilmente puede ser víctima de las amenazas que se le hacen. En este sentido, perciben que quienes los están extorsionando, sobre todo si se identifican como pandilleros, tienen la capacidad y la intención de infligir el daño amenazado. Además tienen poca o ninguna confianza en la efectividad de las autoridades para librarlas de este flagelo, por lo que en muchos de los casos terminan por pagar la cantidad de dinero extorsionada. Las víctimas rápidamente calculan el costo pecuniario de pagar la extorsión al costo del daño que pueden ser sujetos, situación que los extorsionistas hábilmente manipulan a su favor, tomando en cuenta la angustia y temor de sus víctimas.

\subsubsection{Amplificación del fenómeno por los Medios de Comunicación Social.-}

Los medios de comunicación social (MCS), escrito, televisivo, video y servicios de internet, juegan un importante rol en establecer entre la ciudadanía el debate, el discurso, las percepciones del carácter y significado de la violencia y el crimen. El Salvador es una sociedad mediatizada en la cual la principal información sobre el crimen es provista por los diversos MCS. Estos medios están en su mayoría orientados a especular con la violencia, generan en la población una percepción de inseguridad mayor a la que en realidad existe, propiciando a su vez una mayor desconfianza de la población en sus autoridades. Los MCS tienden a vender el concepto en el cual los pandilleros están presentes por doquier y son por doquier temibles, perteneciendo a un mundo totalmente distinto, sin relación a la existencia cotidiana y familiar. Al estigmatizar a los pandilleros como "el otro", "el ajeno", no importa a la población que éstos languidezcan en los centros penales. También la población espantada por la ola de crimen, es presa de políticos, quienes tratando de superar a sus oponentes por votos, buscan aplacar el miedo público, prometiendo mayores condenas de prisión para los delincuentes, agravando al implementarse éstas, la situación en el sistema penitenciario. (UNODC, 2007; Focault, 2002; Richards, Newbold, \& Ross, 2009).

Especial influencia han tenido los MCS en establecer la infame reputación de las pandillas, centrándose en ellos como los principales responsables de la ola de criminalidad que vive el país. En respuesta a este tipo de cobertura, que en parte es alimentada por las autoridades, la presión sobre las instrucciones de seguridad pública es el de enfocar sus esfuerzos en estos GCO. La concentración de titulares en aquellos casos más sangrientos y dantescos genera una gran incertidumbre, miedo, desinformación y especulación en la población, propiciando a su vez que 
ésta requiera la implementación de medidas draconianas para contrarrestar la amenaza. En este orden de ideas, los MCS exageran y sensacionalizan el crimen en su búsqueda por incrementar su porción del mercado. Esta situación ha sido reconocida por el mismo Presidente de la República, Mauricio Funes, periodista de profesión, quien expresamente, luego del terrible incidente de la quema de un autobús, por parte de los pandilleros, en que fallecieron 15 personas, se dirigió a los MCS de la siguiente manera:

\begin{abstract}
“...hay algunos medios de comunicación electrónicos que llevan a cabo una clara campaña psicológica con el fin de desestabilizar y crear pánico en la población. Quiero pedirles a los medios masivos tradicionales, periódicos, radios y televisoras y al resto de los medios, que no se hagan eco de esas campañas desestabilizadoras. Quiero pedirles que no sean cómplices de quienes quieren llevarnos al caos para atacar a las instituciones de la democracia".
\end{abstract}

\title{
2.2.3. Grupos de Crimen Organizado compensan débil o nulo soporte social estatal y déficits de gobernabilidad.
}

Como se ha señalado la otra función con que se mide la capacidad estatal es la función distributiva, su capacidad de inversión social, de reducir la pobreza, mejorar la educación y servicios de salud. La capacidad estatal en este ámbito se ve seriamente comprometida por elevados índices de criminalidad y delincuencia. El crimen erosiona el capital humano y social, destruye las relaciones de confianza en que la sociedad se basa y degrada la calidad de vida. También obstaculiza la educación y la provisión de los servicios de salud, obliga a la inmigración de los trabajadores hábiles hacia el extranjero, a la vez la inseguridad y la victimización interfieren con el desarrollo de aquellos que se quedan en el país. Un alto nivel de criminalidad es nocivo para el comercio, los inversionistas lo interpretan como una señal de inestabilidad social a la vez que eleva el costo de hacer negocios (UNODC, 2007).

En El Salvador la urbanización descontrolada ha generado el aparecimiento de una serie de comunidades marginales, difíciles de controlar y donde pulula la actividad criminal y la expansión de las pandillas. Las grandes concentraciones de personas que habitan en las mismas, inevitablemente provoca la competencia por recursos limitados, expandiendo el estrés y la anomia social. Estas comunidades abandonadas se destacan por una débil presencia del Estado, situación que se refleja en sus pésimas condiciones sanitarias, falta de acceso a agua potable, calles en mal estado, pocas opciones de entretenimiento para sus habitantes, especialmente la juventud y un alto nivel de desempleo y subempleo. Este vacío institucional y socio-económico es rápidamente cubierto por las pandillas u otros GCO, quienes a cambio de disponer de un refugio seguro, buscan compensar a sus pobladores, brindándoles un mecanismo de apoyo y subsistencia ante estas condiciones desfavorables (Hagedorn, 2008; Richani, 2007). El que las pandillas y otros GCO brinden consistentemente un soporte social, económico y de protección a estas comunidades les granjea cierto nivel de legitimidad para su organización, a la vez que establece la lealtad de sus subordinados.

Igual situación se da dentro de los centros penales, donde las precarias condiciones de vida de los presos y el nulo soporte social estatal, buscan ser compensados por las pandillas. Ante su vulnerabilidad dentro de la cárcel los individuos tenderán a ser atraídos por los beneficios que le son proveídos por las redes criminales que operan en su seno. Al permitir que estos GCO prosperen la mayoría de sus 

El Crimen Organizado en las Cárceles:
Las Extorsiones desde los Centros Penales en El Salvador (2008-2009)

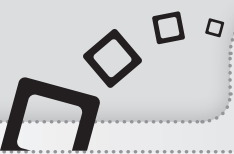

miembros se involucrarán en las actividades ílicitas que permiten que éstos grupos puedan proveer el soporte social que el estado no brinda (Colvin, 2007).

\subsection{Carácter Económico}

El término extorsión designa la presión o las amenazas que una persona recibe para hacer o dejar de hacer algo a cambio de no sufrir daños en su persona, sus bienes o los de sus familiares (Azaola, 2008). Quizás el factor más importante para que el fenómeno de las extorsiones desde los centros penales se esté multiplicando y extendiendo es que resulta una actividad ilegal, que comparada a otros delitos, requiere de poca sofisticación logística y operativa, así como resulta altamente rentable. En lo que respecta a las pandillas se ha convertido en una de las principales actividades a que dedican sus esfuerzos y el medio por el cual mantienen a sus familias.

\subsubsection{La Extorsión: Actividad ilegal de elevadas ganancias y bajos riesgos.-}

De acuerdo a declaraciones realizadas por el entonces Director General de la Policía Nacional Civil, Comisionado Carlos Ascencio Girón los internos de pandillas en los centros penales reciben entre 700 a 800 mil dólares mensuales procedentes de la extorsión (El Diario de Hoy, 2010d). Dicha suma, según la Prensa Gráfica del 9 de enero del 2010 representa un ingreso de 9.6 millones de dólares anuales, cantidad que supera

... Ios \$6.5 millones de presupuesto anual asignado a la Procuraduría para la Defensa de los Derechos Humanos (PDDH), e incluso está arriba de los $\$ 7.5$ millones otorgados el año anterior por el Ministerio de Salud a los hospitales para el refuerzo en la compra de medicamentos....

Los pandilleros al igual que otros actores racionales, calculan el riesgo de ser capturados y el castigo al que se exponen y lo comprarán con los beneficios que obtienen de la extorsión. Si se toma en cuenta que, como ya se señaló, la prisión no es ningún disuasivo para aquellos quienes todos sus compañeros se encuentran internos y que el riesgo primero de denuncia y luego de captura es bastante reducido, es obvio que la opción por la extorsión se torna bastante atractiva. Las alternativas al crimen también son evaluadas por el ingreso promedio obtenido por el crimen versus el salario mínimo, niveles de desempleo, sub-empleo y los niveles promedio de educación de las poblaciones criminales. Un pandillero fácilmente puede estar generando entre 600 a 1,000 dólares mensuales extorsionando, con lo que excede con creces el salario mínimo de los sectores: comercio (\$207.68), industria (\$203.10), textil (\$173.78) y agro (\$97.20) (Revista Summa, 15 de junio 2010). Esta situación aparejada al elevado nivel de desempleo y subempleo, el cual de acuerdo a un estudio alcanza el 50\% (PNUD, 2008), sumado al poco nivel de escolaridad de los pandilleros, torna la extorsión en una alternativa viable para generarse ingresos.

El costo de las extorsiones para el comercio es sustancial, según reportes del Cuerpo de Agentes Metropolitanos, los empresarios de la zona llegan a pagar hasta $\$ 15,000$ dólares mensuales a extorsionistas que operan en el centro de la ciudad y muchas compañías salvadoreñas reportan que aproximadamente el $27 \%$ de todos los crímenes que se perpetraron contra ellos eran producto de extosiones por parte de las pandillas (Cámara de Comercio e Industria de El Salvador, 2010; Millet y Shannon, 2008). 
La existencia de un creciente mercado informal en el país, el cual para el año 2005 proveía el $49.8 \%$ de todos los empleos (FUNDE, 2005), tiene también sus efectos nocivos. La existencia de "mercados negros" siempre ha estado aparejada con la existencia de las GCO o mafias. Estos mercados informales no recurren a los mecanismos legales establecidos para saldar sus cuentas y deudas, sino que éstas son tramitadas a través del accionar de las GCO o mafias. Esta función del crimen organizado de funcionar como estructura de gobernanza de estos mercados muchas veces pasa desapercibida, reduciéndose los esfuerzos de las autoridades a contrarrestar su provisión de bienes y servicios ilícitos (Fiorentini, 1999). La existencia de esta estructura de gobernanza es de tal importancia y generadora de poder para los GCO que algunos autores, inclusive, han llegado hacer la analogía de los pagos de extorsión con los impuestos que cobra el Estado (Grossman y Gambeta en Fiorentini, 1999). También es de hacer notar que las cuantiosas cantidades de dinero que son generadas por las actividades criminales tienen que ser canalizadas tarde o temprano en el mercado formal. Consecuentemente, existe una relación positiva entre el volumen de transacciones en los mercados ilegales y la influencia de los GCO en los mercados legales (Fiorentini, 1999). La reinversión de fondos recaudados por medio de las actividades ilegales en compañías legales socava la economía legítima y genera transtornos en el equilibrio natural del mercado.

\title{
2.3.2. Masificación en el uso de la telefonía celular
}

El crimen organizado ha existido dentro de las prisiones desde la aparición de éstas en el Siglo XIX. En 1845 A. de Tocqueville al referirse al sistema penitenciario en Estados Unidos señalaba que

\begin{abstract}
Existe en este momento entre nosotros una sociedad organizada de criminales... Forman una pequeña nación en el seno de la grande. Casi todos esos hombres se han conocido en las prisiones, en las que vuelven a encontrarse. Es esa sociedad cuyos miembros se trata hoy de dispersar (Foucault, 2002, p.239).
\end{abstract}

Las pandillas en las prisiones, sin embargo, sobre todo las de origen hispano aparecieron a mediados del siglo XX. La Mafia Mexicana (EME) tiene su origen en 1957 en el Instituto Vocacional de Deuel en Tracy, California. La pandilla Nuestra Familia se organiza como rival de la EME en 1967 en la prisión estatal de Soledad en California. Ambas como otras pandillas de prisión de origen étnico (La Hermandad Aria, La Familia Guerrillera Negra y el Sindicato de Texas) rápidamente establecieron su presencia fuera de los confines de las prisiones (Mallory, 2011). La circunstancia que ha convertido a éstos y otros grupos criminales que operan desde las prisiones en una amenaza más presente y peligrosa a la sociedad actual, ha sido la evolución tecnológica en las comunicaciones.

La innovación más influyente en el campo antes referido ha sido sin duda alguna, a la par de la computadora y la telefonía celular. El elemento más importante para que pueda existir una organización y ser eficiente es la comunicación. Los teléfonos celulares han proveído a los GCO en las cárceles de un medio de comunicación barato y fácil. También la evolución tecnológica de los "chips" y micro memorias, los SD también han facilitado y tornado más confiables las comunicaciones entre los miembros de los GCO. Estos últimos son extremadamente valiosos porque permiten a los líderes trasladar directamente, en video, sus órdenes, directrices o mensajes a sus subalternos. El valor del uso de esta tecnología de comunicación para los GCO resulta incuestionable si se considera que más del $75 \%$ de los casos de homicidio agravados, extorsiones y secuestros, que se ventilaron en 2009 en los juzgados contra 
El Crimen Organizado en las Cárceles:
Las Extorsiones desde los Centros Penales en El Salvador (2008-2009)

el crimen organizado y que han ido a juicio, fueron ordenados y ejecutados por medio de la telefonía (Cámara de Comercio e Industria de El Salvador, 2010; López, 2010).

En El Salvador el uso de la telefonía celular se ha extendido a través de toda su población. Entre los años del 2005 al 2009, se pasó de tener alrededor de 2.5 millones de líneas móviles a 7.5 millones, un aumento en cuatro años de alrededor de un $300 \%$ (Gráfico 5) y se calcula que cada seis meses entran en servicio 500,000 nuevas líneas móviles. Esta situación posibilita la disposición de una inmensa cantidad de víctimas.

\section{Gráfico 5 \\ Líneas móviles en El Salvador, 2005-2009}

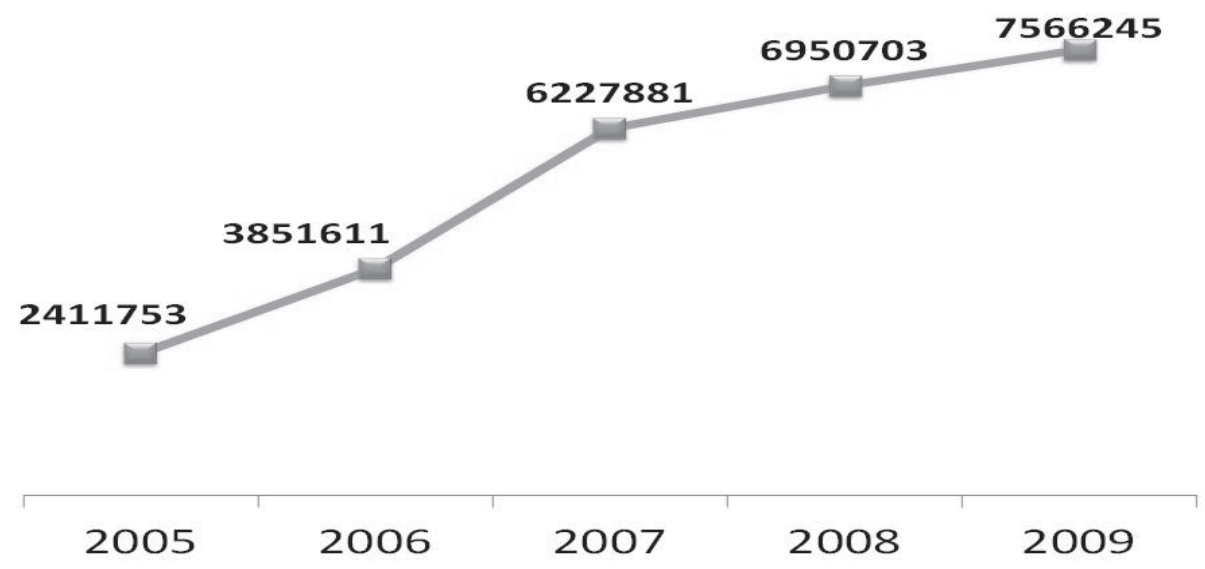

Fuente: Elaboración propia con datos de la SIGET, 2009. Boletín estadístico informativo.

El valor de un teléfono celular, de un chip o memoria dentro de un centro penal está proporcionalmente relacionado con la dificultad que representa el ingresarlos. En el Penal de Máxima Seguridad de Zacatecoluca el costo de un teléfono celular puede rondar los tres mil dólares y un chip o Memoria SD puede costar alrededor de 5 mil dólares. En el resto de centros penales el valor de un teléfono celular es de 300 a 500 dólares $^{10}$. Las maneras que los internos se ingenian para ingresar estos aparatos a los reclusorios son diversas. En el mes de junio de 2010 se incautaron 115 teléfonos que iban escondidos en bandejas de comidad de la empresa que provee la alimentación al penal de Ciudad Barrios, para realizar esta acción se interceptó y retuvo al personal que transportaba y servía el alimento. Este tipo de operaciones revela el nivel de complejidad y organización de las pandillas para poder coordinar y ejecutar las mismas (El Diario de Hoy, 2010a).

A pesar de los esfuerzos de las autoridades el ingreso de teléfonos celulares, chips y memorias SD a las prisiones resulta imparable. Las siguientes cifras reflejan la dimensión de este problema, en el año 2004 se reportó el requiso de 50 telefónos celulares y 150 chips, durante el año 2009 esta cifra aumentó substancialmente habiéndose requisado 2,919 teléfonos celulares y 1,394 chips (Gráfico 6).

10 Entrevista realizada por el autor a Experto Centro Antipandillas Transnacional Policía Nacional Civil. 01 de julio 2010 


\section{Gráfico 6 \\ Celulares, cargadores y chips requisados en Centros Penales 2005-2009}

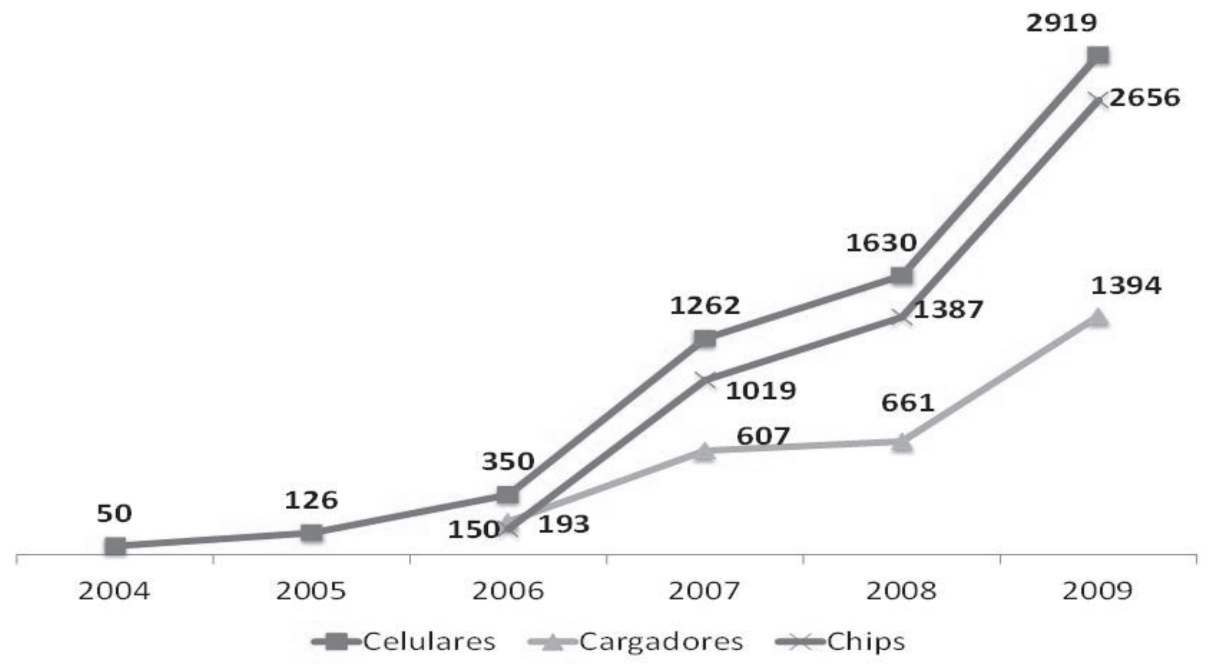

Fuente: Elaboración propia con información de la Dirección General de Centros Penales

Últimamente para impedir el uso de celulares en los centros penales ha entrado en vigencia una nueva ley de intervención de las comunicaciones en la cual se prohíbe la tenencia de números privados y se establecen mayores controles para aquellas líneas telefónicas que funcionan con el sistema de prepago. También se han instalado bloqueadores de teléfonos y se ha desplegado a la Fuerza Armada para que extienda un cordón de seguridad alrededor de los penales que inhiba el contrabando de estos aparatos y otros objetos no permitidos.

\section{Características de los Tipos de Extorsiones desde las Cárceles en El Salvador ${ }^{11}$}

Las extorsiones en general siguen un patrón que se puede dividir en 4 etapas: a) selección de la víctima b) la negociación, c) la entrega de dinero y d) la distribución del producto de la extorsión. En cada una de estas etapas participan varios actores pertenecientes a los GCO o relacionados con éstos.

La selección de la víctima es llevada a cabo por parte de pandilleros que se encuentran en libertad, colaboradores o familiares de los pandilleros. El criterio que prevalece en la selección es la capacidad de pago de la víctima o alguna característica o circunstancia que la torne valiosa para la pandilla. En esta fase lo que se procura es conseguir la mayor cantidad de información personal de la víctima, sus familiares o negocio, la cual será de gran utilidad en convencer a ésta de su estado de vulnerabilidad frente a los extorsionistas.

11 La información recabada en este capítulo es producto de entrevistas realizadas por el suscrito con expertos de la División de Investigación de Extorsiones y del Centro Antipandillas Transnacional de la Policía Nacional Civil, en los mese de junio y julio de 2010. 

El Crimen Organizado en las Cárceles:
Las Extorsiones desde los Centros Penales en El Salvador (2008-2009)

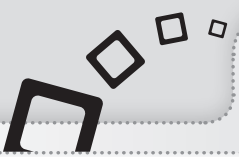

La negociación es la etapa en que se contacta a la víctima, generalmente es llevada a cabo por los pandilleros que se encuentran internos en los diversos centros penales. Este contacto se Ileva a cabo la mayoría de veces vía telefónica ( $87 \%$ de los casos) por medio de anónimos o contacto directo con la víctima.

Durante la negociación, aprovechando la angustia y temor de la víctima, se hace la exigencia, la cual es determinada de acuerdo a la capacidad y comportamiento de la víctima durante este proceso. Esta exigencia no solamente puede ser el pago de una determinada cantidad de dinero sino también en tarjetas pre-pago de teléfono, chips para celulares, productos diversos o favores. Asimismo se acuerda la fecha y forma de entrega y se externa la amenaza, la cual puede ser de muerte o a la integridad física de la víctima o sus familiares, de daños a su propiedad y bienes o de secuestro. En el país se dan dos modalidades de extorsión: a) la "extorsión única" en la cual se exige un solo pago a la víctima. La mayoría de estas son personas particulares y en estos casos los extorsionistas suelen no manejar mucha información relacionada con ésta y; b) "extorsión periódica", en la cual la víctima hace pagos periódicamente por lo general diarios o semanales. En estos casos los extorsionistas manejan una gran cantidad de información sobre las víctimas.

La entrega de dinero es la etapa, más vulnerable para el extorsionador, en ella se involucran una serie de actores, los que van hacer la recepción, los vígias y los que les bridan seguridad. Los lugares que se escogen para recibir el pago, son aquellos que garanticen la menor exposición para los extorsionistas: sectores de dominio territorial de las pandillas, rutas de transporte, paradas de autobuses y mercados. También a veces se exige que los pagos se hagan en forma de depósitos a varias cuentas bancarias nacionales o en el extranjero.

La distribución del producto de la extorsión se lleva a cabo entre todos los que participaron en la misma, en la cual cada actor recibe "la tajada" preacordada. En las pandillas se ha establecido un sistema por medio del cual sus miembros pagan cuotas periódicas que alimentan un fondo común. Este dinero luego es utilizado para casos de emergencia, la compra de munición y armas, pago de abogados, sobornos y para dar soporte económico a los pandilleros y sus familias.

Las extorsiones son clasificadas de acuerdo a su peligrosidad hacia el sujeto a que se dirigen y complejidad en su ejecución, en:

\section{Peligrosidad y complejidad baja}

Este tipo de extorsión se dirige primordialmente a personas particulares. En este tipo de extorsión, como ya se mencionó el extorsionista maneja poca información sobre la víctima, el peligro de que la amenaza sea ejecutada por parte del extorsionista es baja y el nivel de complejidad requerido para llevar a cabo la misma es mínimo. La mayor parte de estos casos se tratan de extorsiones únicas.

\section{Peligrosidad y complejidad media}

Estas extorsiones se identifican como de proximidad, se caracterizan por ser cometidas por personas que tienen algún tipo de vínculo con la víctima, la conocen bien. En estos casos la vulnerabilidad de la víctima es mayor dado que está constantemente vigilada por el extorsionador y conoce sus debilidades. La complejidad de ejecutar la extorsión se dificulta medianamente por el vínculo cercano del extorsionador con la víctima, la cual en cualquier momento puede llegar a reconocerlo o a descubrirlo. 


\section{Peligrosidad y complejidad alta}

En este tipo de extorsiones se necesita de una mayor organización y se coordinan una serie de acciones para poder ejecutarlas exitosamente. Entre ellas se destacan tres tipos:

1) De carácter transnacional; son ejecutadas por GCO con gran capacidad de planificación, coordinación y ejecución. En estos casos la actividad delictiva traspasa las fronteras nacionales, involucrando dos o más Estados. En una reciente red de extorsión que se desmanteló en el país, ésta operaba desde varios de los centros penales del país, desde donde se realizaban extorsiones a personas residentes en los EEUU a quienes se exigía que realizaran sus pagos en forma de encomiendas o remesas hacia determinadas personas en El Salvador. En la red participaban 50 miembros, 14 de los cuales residían en los estados de Nueva York y Virginia, apoyados por 20 personas más, entre las cuales se encontraban madres, esposas, novias y amigos de los delincuentes. Durante el tiempo que operaron realizaron alrededor de 90 extorsiones (La Prensa Gráfica, 2010d). Dado su nivel de organización su peligrosidad resulta evidente;

2) Las que se dirigen a la industria y el comercio, estos sectores generalmente son víctimas de la extorsión periódica. En muchos de los casos están involucrados empleados de las empresas, ya sea como cómplices directos o que aprovechan la ocasión para exigir más de lo que en realidad les están exigiendo, apropiándose de este excedente. También a estos negocios les pueden exigir dinero en concepto de brindarles servicios de protección. El problema que afecta a estas empresas es serio, ya que evidentemente les eleva sus costos. A manera de ejemplo de acuerdo a la Cámara de Comercio e Industria de San Miguel, el $80 \%$ de sus miembros son víctimas de extorsionistas, algunos de los que se ven obligados a pagar entre 1,200 y 1,400 dólares mensuales (UNDOC, 2007). También la peligrosidad que representa para la integridad de aquellos empresarios que no pagan, sus familiares, conocidos y bienes es elevada, debido a que este tipo de extorsión es ejecutada por una GCO bien organizada con la capacidad de llevar a cabo sus amenazas. Estas extorsiones son de una ejecución compleja que demanda planificación, coordinación y redes de cobro.

3) Las dirigidas al sector transporte, este sector es sin duda alguna el más afectado y envuelto en una espiral de violencia, debido a que muchos pandilleros trabajan o han trabajado en el sector como motoristas o cobradores y por lo tanto conocen a fondo la industria. También la vulnerabilidad de las unidades de transporte público es obvia, sobre todo aquellas que circulan en los sectores de dominio territorial de las pandillas. A muchas unidades de transporte les es exigido el pago de entre tres a cinco dólares diarios para que se les permita operar con seguridad o el pago semanal de 20 a 50 dólares semanales por unidad. El nivel de peligrosidad a que está expuesto este sector se refleja en el hecho de que entre el año 2006 a junio de 2010, 510 personas relacionadas al transporte han sido asesinadas (Diario de Hoy , 2010e).

\section{Conclusiones y Reflexiones Finales}

El crimen organizado desde los centros penales se constituye en una amenaza a la seguridad del Estado de El Salvador. La actividad ilegal de estas organizaciones criminales socava la habilidad del Estado para proveer servicios, proteger a las 

El Crimen Organizado en las Cárceles:
Las Extorsiones desde los Centros Penales en El Salvador (2008-2009)

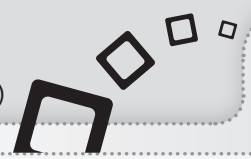

personas y mantener la confianza de la ciudadanía en el gobierno y la democracia. Asimismo generan nuevas formas de violencia, amenaza la soberanía, debilita las instituciones y afecta el mantenimiento de los valores públicos.

Las autoridades estatales deben abordar el fenómeno de las extorsiones estratégicamente y no reactivamente. Una aproximación estratégica se enfoca en cómo pensar, entender cómo se puede desarrollar una perspectiva para definir y seleccionar las opciones alternativas en una incrementalmente compleja y dinámica realidad. También implica el dilucidar cómo articular opciones que puedan ser comprendidas e implementadas. La estrategia a todos los niveles implica el cálculo de objetivos, conceptos y recursos dentro de límites aceptables de riesgo a efecto de generar resultados más favorables que los que pudieran existir al azar o en las manos de otros.

La complejidad de la dinámica del fenómeno de la extorsión en El Salvador se puede apreciar a partir del modelo sistémico que se elaboró para llevar a cabo la aproximación al análisis y comprensión de éste y los factores criminógenos que se conjugan para fomentarlo (Figura 4).

El modelo resulta de gran utilidad para identificar los ciclos de retroalimentación y el balance entre ellos. Asimismo sirve como un instrumento para el desarrollo de la estrategia al permitir un análisis de las opciones de intervención desde una perspectiva sistémica a partir de la identificación de sus centros de gravedad.

La simple vista del modelo nos señala el hecho de que la mayor cantidad de ciclos de retroalimentación (CR) que inciden en el fenómeno de las extorsiones en El Salvador se dan dentro del ámbito político gubernamental. Esta situación resulta favorable en la búsqueda de la solución al problema en el sentido de que muchas de las variables que conforman los CR dependen de la misma actividad estatal y por lo tanto se requiere de la voluntad política y el abordaje estratégico de éstos para lograr incidir positivamente en su dinámica (Figura 5). 

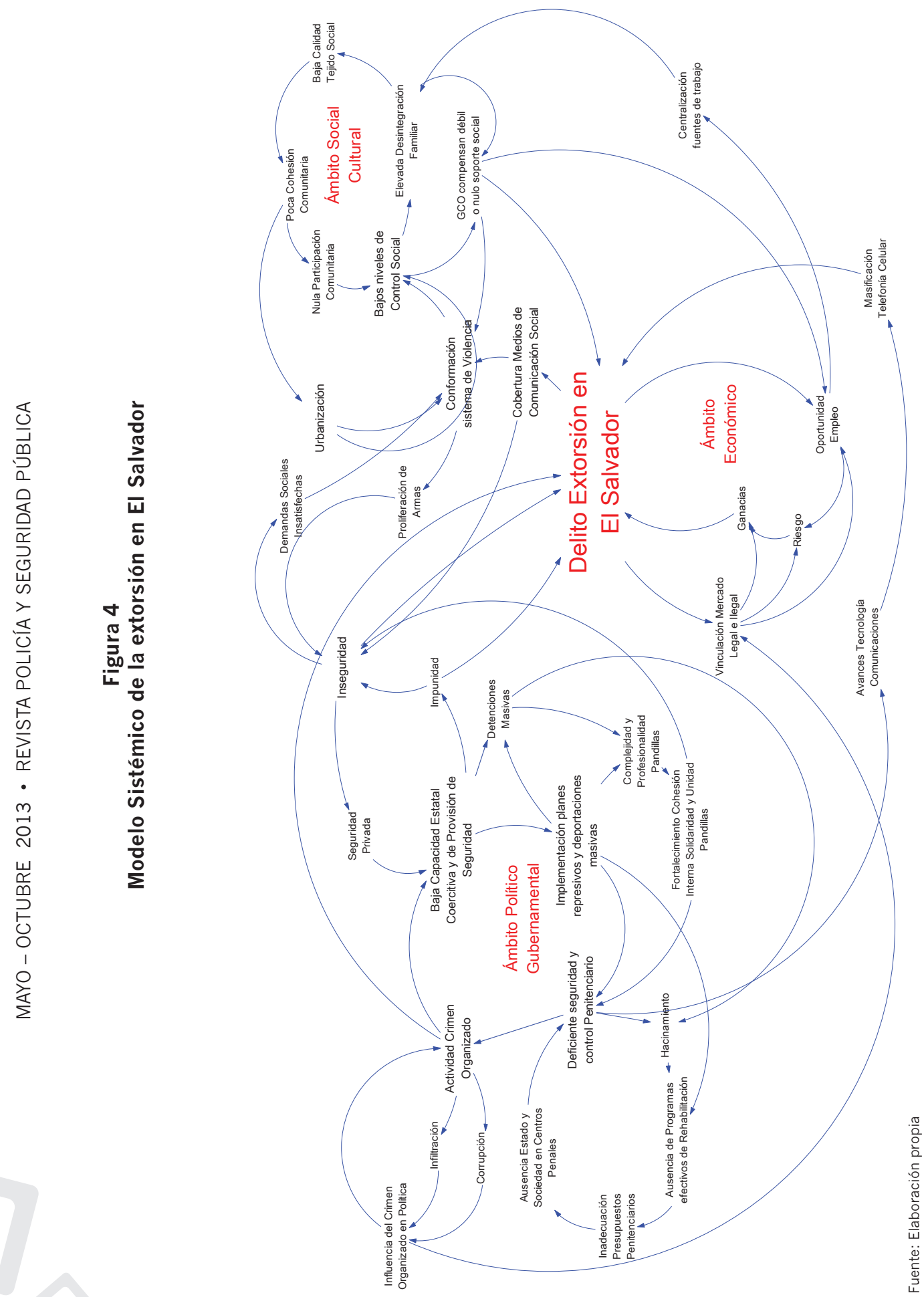
El Crimen Organizado en las Cárceles:
Las Extorsiones desde los Centros Penales en El Salvador (2008-2009)

Figura 5

Dinámica de la Extorsión en El Salvador Ámbito Político Gubernamental

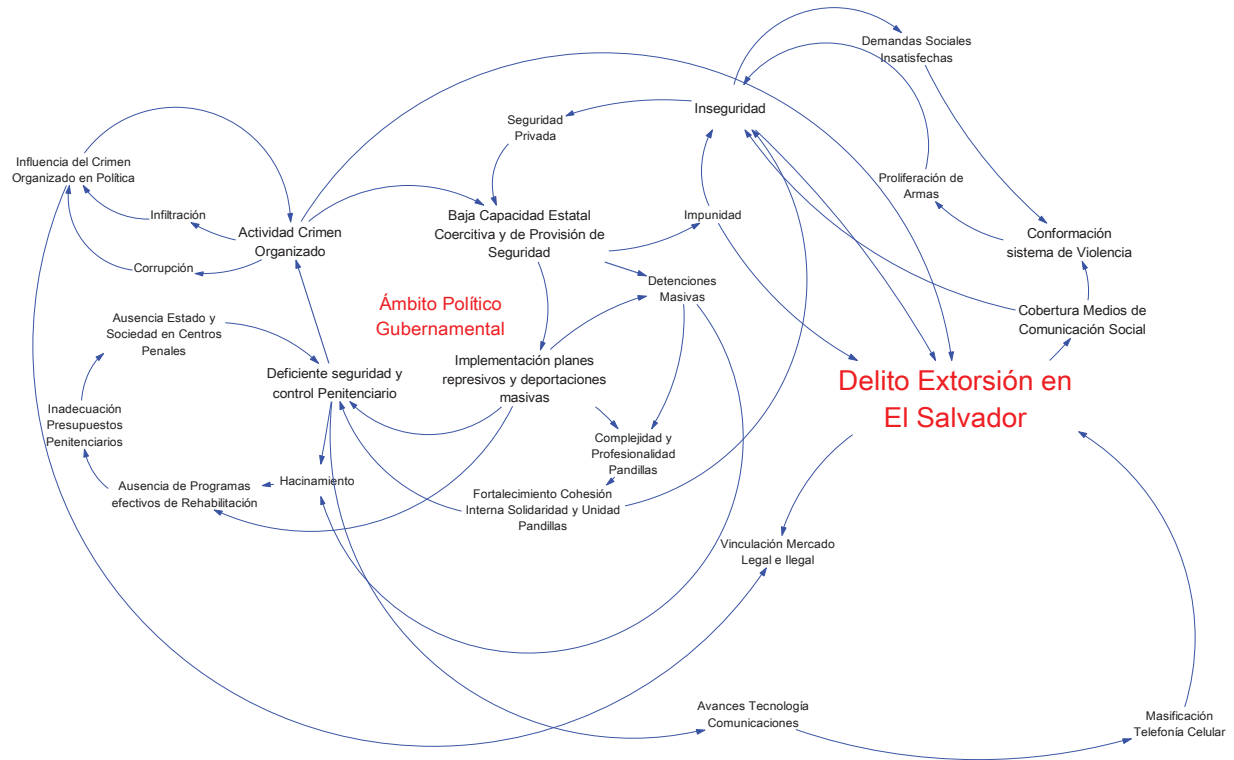

Fuente: Elaboración propia

\section{Ámbito Político Gubernamental}

Del análisis de la parte del modelo que corresponde al ámbito político gubernamental (Figura 5) se identifican los siguientes centros de gravedad que afectan todas las variables en este ámbito: a) la deficiente seguridad y control penitenciario b) la baja capacidad estatal coercitiva y de provisión de seguridad; c) la implementación de planes represivos y las deportaciones masivas; y d) la actividad de grupos de crimen organizado dentro y fuera de las prisiones.

Ante lo expuesto, las medidas que se podrían adoptar deben estar orientadas a influir en estos centros de gravedad a fin de que incidan positivamente en la dinámica de los CR. En este sentido, se recomienda:

Implementar políticas de Estado consistentes y duraderas que conlleven a la superación del problema. En este orden de ideas se debe:

a) Mejorar la seguridad y control penitenciario. El Estado debe procurar administrar el hacinamiento en los centros penales dado que la relación de esta variable con la seguridad y control de los mismos es proporcionalmente inversa. A mayor hacinamiento se ejerce menor control y disminuye la seguridad dentro de los centros penales. Una medida que inmediatamente afectaría el nivel de hacinamiento es la de evitar el hacer detenciones masivas, cuyo único propósito es el demostrar que el gobierno está implementando medidas draconianas para solventar el problema de la criminalidad y sobretodo de las extorsiones.

Otra medida importante a implementar sería el de reestructurar el sistema penitenciario a fin de que brinde un trato que dignifique a los internos y les 
provea una verdadera oportunidad de reinserción social. El ocio es uno de los grandes problemas que se enfrentan dentro de las prisiones. Un grupo de internos a los cuáles no se provean actividades alternas, rápidamente va a decantar sus esfuerzos en pensar cómo y de qué manera ejecutar actividades ilícitas desde las prisiones.

También las autoridades penitenciarias deben garantizar la seguridad y derechos de los internos. En este sentido, debe equilibrar su prioridad a la seguridad al brindar el debido tratamiento, velar por la salud y la correcta administración de los internos. Obviamente una buena administración de los centros penales transita por el hecho que se le asigne un presupuesto adecuado para cumplir su compleja misión.

La construcción de centros penales modernos cuyas instalaciones faciliten el control y seguridad de los internos, que permita la segregación de éstos por su nivel de peligrosidad, así como faciliten los programas de reinserción y rehabilitación sería un paso correcto en la solución de problemas. Sin embargo hay que considerar que esta opción es la que presenta los mayores costos.

Finalmente bajo este rubro se debe procurar el aumentar tanto la presencia del Estado en los niveles de control, seguridad y bienestar de los centros penales como la presencia de la sociedad civil en los aspectos relativos a la rehabilitación y reinserción social. En las prisiones no deben existir vacíos que puedan ser cubiertos por los GCO. El control del contrabando de teléfonos celulares, chips, drogas, armas, etc. hacia dentro de las prisiones debe ser una prioridad. En esta actividad de interdicción se debe dar paso a la utilización de técnicas y medios de registro menos intrusivas que no vulneren la dignidad tanto de los internos como de aquellas personas que los visitan. También el Estado debe mejorar la selección, la preparación y soporte de los agentes penitenciarios haciendo especial hincapié en su formación deontológica. La implementación de la Política Penitenciaria "Carreteras de Oportunidad con Justicia y Seguridad", por parte de la Dirección General de Centros Penales, el fortalecimiento de la Escuela Penitenciaria y mejoras en el proceso de selección y capacitación de los agentes penitenciarios se considera son pasos en el rumbo correcto.

b) Tomar medidas que permitan elevar la capacidad estatal coercitiva y de provisión de seguridad. En lo concerniente a la capacidad coercitiva el Estado lo importante radica en que pueda ser efectivo con su cometido de hacer cumplir la ley. Esta situación implica mejorar la efectividad y eficiencia de la Policía Nacional Civil, promoviendo avances en las áreas de inteligencia, investigación y de prevención, más que en su capacidad represiva. También se debe mejorar el sistema de justicia que permita la aplicación de la ley de manera equitativa, pronta y justa. En esta área es importante la capacitación de jueces y colaboradores jurídicos, así como también tomar las medidas que garanticen su seguridad.

El logro de avances en los campos referidos incidirá en que se reduzca en el país la impunidad. El elevar los riesgos para los actores ilegales que se dedican a lo ilícito tendrá un impacto positivo en la seguridad de la población. Al ir mejorando la seguridad objetiva y subjetiva de la población el gobierno no sólo gana legitimidad al satisfacer esta demanda, sino también inhibe a que las 

El Crimen Organizado en las Cárceles:
Las Extorsiones desde los Centros Penales en El Salvador (2008-2009)

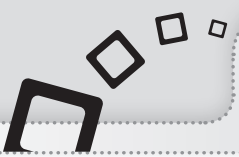

personas quieran hacer justicia con sus "propias manos". Esta situación tendrá un impacto positivo en debilitar la conformación de un sistema de violencia, lo que a su vez disminuirá la proliferación de armas legales e ilegales. El menor número de armas en circulación y mejores controles sobre las mismas y quienes las portan redundará en una reducción de los niveles de inseguridad.

c) Uno de los primeros indicadores con que los gobiernos están abordando la extorsión estratégicamente, va a ser el cese de la implementación de planes represivos como la principal medida para la resolución del problema. Las detenciones masivas que han resultado de la ejecución de los referidos planes, han generado efectos contraproducentes no sólo porque han agravado la situación de hacinamiento en los centros penales sino porque también han propiciado un mayor grado de complejidad y profesionalización de los GCO. Esta última circunstancia ha sido producto de la recomposición de la estructura de los GCO que operan dentro y fuera de los penales, brindándoles mayor cohesión, unidad, resiliencia, solidaridad y sentido de pertenencia.

d) El Estado de El Salvador deben coordinar políticas y esfuerzos sobre todo con los EEUU para evitar las deportaciones masivas. Ambos Estados deben comprender que esta medida no es favorable al largo plazo para ninguno de ellos. Las deportaciones afectan al Estado salvadoreño sobrecargando el soporte social estatal y su capacidad para recibir y administrar a los deportados, en especial aquellos con antecedentes criminales. Las deportaciones van en detrimento de los intereses de ambas naciones al propiciar las condiciones que han facilitado su transnacionalización y la propagación de la cultura pandilleril y su actividad criminal en toda la ruta hacia el norte.

e) El Estado debe interferir y desarticular la actividad de grupos de crimen organizado dentro y fuera de las prisiones no sobre la base de la fuerza sino con trabajo de inteligencia e investigación. Un componente esencial en el combate a estos grupos que pasa inadvertido es el trabajo de depuración y control interno de todas las instituciones encargadas de la aplicación de la ley y el sistema judicial. El esfuerzo en esta vía debe ir dirigido a evitar la corrupción e infiltración de los GCO en estas instituciones y a la depuración de aquellos elementos corruptos o infiltrados dentro de sus filas.

\section{Ámbito Cultural Social}

El punto de partida en este ámbito debe ser el reconocimiento que una exitosa intervención estatal en la esfera social-cultural va a requerir de un esfuerzo continuado por lo menos de dos a tres generaciones. La circunstancia anterior obliga a que el abordaje de la problemática desde este ámbito sea a través de la implementación de políticas de Estado que trasciendan la alternancia o cambios de gobierno. Los principales centros de gravedad que se identifican para la superación del problema de las extorsiones en el país son (Figura 6): el mejorar los niveles de control social; la desarticulación de la dinámica que está generando el sistema de violencia actualmente; el reducir la percepción de inseguridad dentro de la población y; el ampliar el soporte social estatal y la presencia del Estado en todas las comunidades sobre todo en aquellas menos favorecidas. 


\section{Figura 6}

\section{Dinámica de la Extorsión en El Salvador Ámbito Social Político}

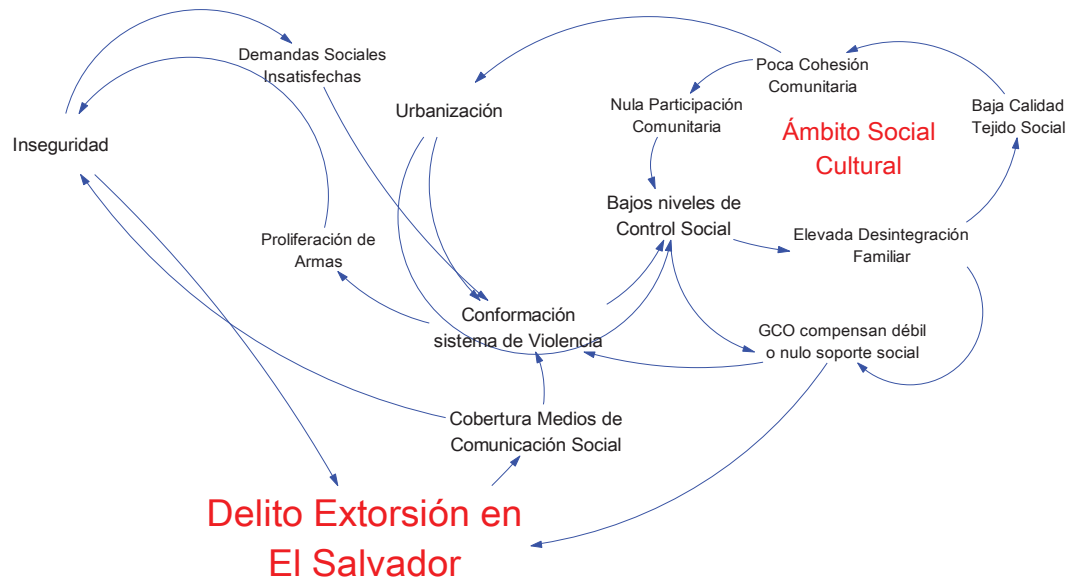

Fuente: Elaboración propia

\section{En este ámbito el Estado debe:}

a) Dirigir todos sus esfuerzos en la reconstrucción del tejido social del país. La mejora de los niveles de control social, dada su importancia y carácter vertebrador de otra serie de variables que dependen de ello, debe ser un objetivo nacional de carácter permanente. Consecuentemente, debe darse prioridad a medidas que fomenten el fortalecimiento de la familia así como la cohesión comunitaria y eleven el nivel de participación de sus miembros en la resolución de sus problemas. Una comunidad sólida, unida, cohesionada, solidaria y participativa se conforma en un bastión impugnable para todo tipo de crimen y delincuencia. Esta participación comunitaria debe incluir y no excluir a los pandilleros. No sólo merecen reconocimiento como personas sino que también son parte de las redes comunitarias. Además no hay que olvidar que la causa primordial de muchos tipos de violencia tienen en sus génesis la exclusión o la marginalización de ciertos colectivos sociales.

b) El desarticular la dinámica que genera un sistema de violencia implica también un esfuerzo a largo plazo y de vital importancia estatal ya que está en juego su monopolio sobre el uso de la fuerza. El Estado debe promover a nivel educativo la cultura de paz. Debe enseñarse a la comunidad a rechazar la fuerza y el dominio como recursos para la resolución de los conflictos por la vía de la imposición. La prioridad en la resolución de problemas entre personas y comunidades debe centrarse en la razón, la comprensión, la comunicación y la capacidad de ceder en aras del beneficio de todos. Igualmente es necesario regular la transmisión de ciertas películas, programas de televisión, comerciales y música que alientan la violencia sobre todo en la juventud y romantizan la figura del bandido, el "capo" o el "narco". A su vez es importante fomentar la enseñanza de valores como: la tolerancia, la cívica, la disciplina, el trabajo y la honestidad entre otros. También el Estado debe hacer efectivos e eficientes sus mecanismos de resolución de conflictos a fin de que recupere 
El Crimen Organizado en las Cárceles:
Las Extorsiones desde los Centros Penales en El Salvador (2008-2009)

la confianza de la ciudadanía y está ya no se vea obligada a recurrir a tomar justicia por sus "propias manos".

c) El Estado debe detener la urbanización desmedida, no planificada y buscar que los complejos habitacionales que se desarrollen no sólo llenen las expectativas de lucro de los empresarios sino las necesidades de espacio, esparcimiento y dignidad que permitan el desarrollo de las personas. Hay que recordar que el hacinamiento habitacional y las condiciones inadecuadas de vivienda influyen en generar conductas violentas en quienes la sufren.

d) Todos los esfuerzos del Estado salvadoreño deben encaminarse a generar las condiciones objetivas y subjetivas para mejorar la seguridad de la población. El éxito en este cometido no sólo generará elevados niveles de legitimidad sino también va a disminuir considerablemente el delito de extorsión. En la medida que las personas se sientan más seguras van a ser menos proclives a ser víctimas de la extorsión. En este campo se debe dar prioridad, como ya se ha señalado, a la prevención, inteligencia e investigación así como al fortalecimiento de las redes de control social comunitarias. En lo que respecta a la percepción de seguridad se debe hacer conciencia en los medios de comunicación social del daño que ocasionan las noticias "amarillistas" y sensacionalistas. Estos medios tienen la obligación y el deber patriótico de reportar la noticia pero no de magnificarla en el afán de lucrarse de ella.

e) El Estado debe elevar su presencia y mecanismos de soporte social en todas las comunidades sobre todo en aquellas menos favorecidas. Consecuentemente no sólo debe tener presencia de las instituciones de aplicación de la ley, sino también en las áreas de salud, educación, cultura, deporte y otras que tienen un impacto en la mejora de la calidad de vida. Siempre hay que tener presente que todo vacío que deje el Estado en este rubro rápidamente va ser cubierto por los GCO a cambio de obtener lealtad y protección de las comunidades a las cuales beneficia.

\section{Ámbito Económico}

Al analizar la parte del modelo que versa sobre el ámbito económico (Figura 7) se puede apreciar que la dinámica de las variables que tiene influencia y fomentan el fenómeno de la extorsión se pueden sintetizar en: que es una actividad ilícita de alta rentabilidad y bajo riesgo; que la extorsión se configura en una alternativa viable de empleo provista por GCO para miembros de comunidades con débil o nulo soporte social; que esta actividad depredatoria es favorecida por el nexo que se forja entre los mercados ilegales y legales en la medida que la actividad de las GCO incrementan sus actividades ilícitas e influencia política y; la extorsión es facilitada por los avances tecnológicos en las comunicaciones y la masificación de la telefonía celular. Por tanto en este ámbito el Estado debe: 
Figura 7

\section{Dinámica de la Extorsión en El Salvador Ámbito Económico}

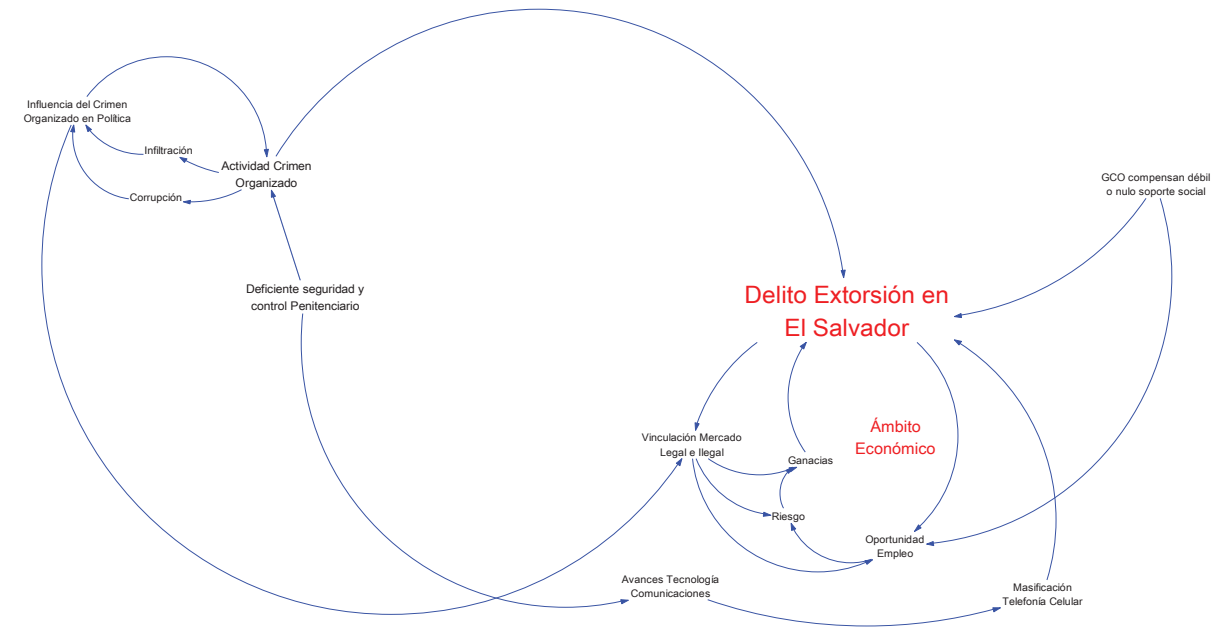

Fuente: Elaboración propia

a) Tomar medidas para hacer de la extorsión una actividad menos rentable y de mayor riesgo. Obviamente el factor de la rentabilidad de las extorsiones va a ser difícil que pueda ser controlada por el Estado, sin embargo sí puede incidir en hacer que esta práctica sea de mayor riesgo para los extorsionistas. Algunas medidas que se pueden implementar son: promover la denuncia entre la población, mejorar la seguridad en las comunidades y sectores comerciales e incrementar las capacidades de investigación e inteligencia. Todas las medidas señaladas van dirigidas a disminuir los niveles de impunidad que hacen que la extorsión sea una actividad atractiva para los GCO sobre todo de aquellos que operan desde los centros penales.

b) Generar alternativas de empleo tanto para los internos de los centros penales como para sus familiares para que reduzcan la dependencia de los ingresos provenientes de la extorsión. Esta opción es de difícil implementación dada la rentabilidad que genera esta actividad ilícita, la cual difícilmente puede ser sustituida por ingresos provenientes de empleos legales sobre todo de jóvenes con poca educación y preparación. La enseñanza de oficios, la conformación de cooperativas o cualquier otra opción en que se pueda utilizar las estructuras organizativas de estos GCO pueden ser algunas medidas que se pudieran implementar en este ámbito. También debe favorecerse la descentralización de las fuentes de trabajo, dando prioridad para la instalación de las mismas cerca de aquellas comunidades vulnerables y con altos índices de desempleo. Estas medidas no solo permitirán que las personas puedan trabajar cerca de lugares donde moran, facilitando que pasen más tiempo con su familia sino también va a brindar una alternativa para el trabajo ilícito.

c) Controlar el aumento de los mercados informales a efecto de administrar el poder que los GCO ejercen sobre éstos y evitar que las ganancias que generan 


\section{El Crimen Organizado en las Cárceles: \\ Las Extorsiones desde los Centros Penales en El Salvador (2008-2009)

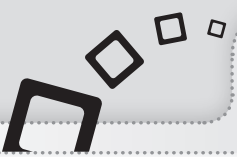

pasen al mercado legal. También el Estado debe mejorar su control sobre los flujos de dinero en la economía formal y fiscalizar muy de cerca todas sus actividades. Otra medida que se puede implementar en este campo es el de evitar las regulaciones innecesarias dado que en muchas ocasiones los aumentos de precios que éstas ocasionan en el mercado legal, hacen que muchos de sus productos y servicios se trasladen a la economía informal. En lo que respecta a la influencia política de los GCO se debe tomar medidas tales como, trasparentar los fondos de financiamiento de campañas electorales, para el control de la corrupción e infiltración de políticos

d) Establecer mayores controles sobre la telefonía celular que permitan ayudar en la identificación de los perpetradores de las extorsiones. Asimismo hay que tomar en cuenta que los avances de la tecnología en comunicaciones deben contrarrestarse también con la adquisición de tecnología para el bloqueo de llamadas desde los centros penales y otras que aumenten la capacidad de las autoridades para poder rastrear e intervenir las comunicaciones, guardandóse el debido respeto de todas las garantías constitucionales.

Finalmente en todos los ámbitos se debe buscar e incluir la ayuda y cooperación internacional y de las organizaciones no gubernamentales en el trato del fenómeno. El compartir experiencias y recursos permitirá el encontrar soluciones viables y sustentables al problema de las extorsiones en el país.

A manera de conclusión ante todo se debe considerar que en lo que respecta a las prisiones no sólo se confinan cuerpos sino seres humanos, que sienten y piensan. La única forma de lograr su rehabilitación es tratándolos dignamente y con justicia. Caso contrario siempre prevalecerán espíritus y actitudes desafiantes ante el Estado por parte de los internos. Lo anterior lo reflejó bien, Huey P. Newton de las Panteras Negras, cuando cuestionó ¿Prisión donde está tu victoria? 


\section{Bibliografía}

\section{Libros e informes}

1. Cámara de Comercio e Industria de El Salvador (2010). "Propuestas para el Combate Integral de la Delincuencia en el Salvador", febrero 2010.

2. Dammert, Lucía y Liza Zúñiga (2008). "La cárcel: problemas y desafíos para las Américas", FLACSO Chile.

3. Davis, Ángela (1972). "La rebelión de Attica", en id. Et al., "Si llegan por ti en la mañana...vendrán por nosotros en la noche", México, Siglo XXI Editores, 1972.

4. Demoscopía (2007). "Maras y Pandillas, Comunidad y Policía en Centroamérica". ASDI, Guatemala. http://biblio3.url.edu.gt/ Libros/2012/ma_pandillas.pdf

5. Dirección General de Estadísticas y Censos (2008). "VI Censo de Población y V de Vivienda 2007". San Salvador: Ministerio de Economía, El Salvador

6. FESPAD (2007). "Más cárcel como política de estado". Año II, N 26. Mayo 2007.

7. Fiorentini, G. (1999). "Organized Crime and Illegal Markets". Dipartimento di Scienze, Economiche, Università di Bologna, http://encyclo.findlaw. com/8400book.pdf.

8. FLACSO, IEPADES (2006). "Informe Subregional Centroamérica y Panamá: Armas Pequeñas y Ligeras". San José, Costa Rica.

9. Foucault. Michel (2002) "Vigilar y Castigar", Siglo XXI, Editores Argentina

10. Fundación Nacional para el Desarrollo [FUNDE] (2005). "Área Macroeconomía y Desarrollo. Desempeño económico y del mercado de trabajo de El Salvador 2004-2005", San Salvador, Global Policy Network.
11. Gaes, Gerald G., Susan Wallace, Evan Gilman, Jody Klein-Saffran, y Sharon Suppa (2001), "The Influence of Prison Gang Affiliation on Violence and Other Prison Misconduct", en The Prison Journal, vol. 82 no. 3, p. 359. 385, recuperado de: http://tpj. sagepub.com/content/82/3/359. abstract

12. Gutirrez, Ral (2008). "El Salvador: Murder of Inmates Reveals Insecurity of Prisons". Global Information Network. Retrieved November 20, 2009, from Research Library. (Document ID: 1447864721). Mar.17 2008.

13. Hagedorn, J. M. (2008). "World of Gangs". Minneapolis: University of Minnesota Press.

14. Jary, D., \& Jary, J. (1991). "Diccionario de Sociología". New York: Harpers Collins.

15. Macaluso, Mike, (2010). "Argot." Encyclopedia of Prisons \& Correctional Facilities. 2004. SAGE Publications. 9 Apr. 2010.

16. Mallory, Stepehn L. (2011). "Understanding Organized Crime", Jones \& Bartlett Publishers, Ontario, Canada.

17. Passas, Nikos. (2000). "Crossborder crime and the interface between legal and illegal actors, Upperworld and Underworld in Cross-border Crime". Petrus C. van Duyne, Klaus von Lampe, Nikos Passas (Eds.).Published by Wolf Legal Publishers (WLP).

18. Programa de Naciones Unidas para el Desarrollo [PNUD] (2005). "Informe sobre Desarrollo Humano El Salvador 2003". San Salvador: Programa de Naciones Unidas para el Desarrollo, 1a. ed.

19. Programa de Naciones Unidas para el Desarrollo [PNUD] (2008). "El empleo en uno de los pueblos más trabajadores del Mundo: Informe sobre Desarrollo Humano El Salvador 2007-2008", San 
El Crimen Organizado en las Cárceles:
Las Extorsiones desde los Centros Penales en El Salvador (2008-2009)

Salvador, Programa de Naciones Unidas para el Desarrollo.

20. Richani, Nazih. (2007). "Systems of Violence and their Political Economy in Post-Conflict Situations". Kean Univesity, http://siteresources. worldbank.org/INTCONFLICT/ Resources/RichaniRvsd2007.doc

21. United Nations Office on Drugs and Crime [UNODC] (2007). "Crime and development in Central America". United Nations Publication http:// www.agora-parl.org/sites/default/ files/crime_and_development_in_ central_america_2007.pdf

22. Von Lampe, Klaus (2003). "The Use of Models in the Study of Organized Crime Paper presented at the 2003 conference of the European Consortium for Political Research (ECPR)". Marburg, Germany, 19 September 2003.

23. Williams Phil \& Roy Godson (2002). "Anticipating Organized and Transnational Crime, Crime, Law and Social Change", Jun 2002, 37, 4; Kluwer Academic Publishers.

\section{Revistas}

1. Aguilar Villamariona, Jeannette (2008). "Los efectos contraproducentes de los Planes Mano Dura", Quórum, Revista de Pensamiento Iberoamericano, Invierno, No. 016, Universidad de Alcalá, Madrid, España.

2. Azaola, Elena (2008). "El comercio con el dolor y la esperanza. La extorsión telefónica en México". Urvio, Revista Latinoamericana de Seguridad Ciudadana. No. 6, Quito, Enero 2009, pp. 115.122, FLACSO, Ecuador.

3. Bailey, John and Matthew M. Taylor (2009). "Evade, Corrupt, or Confront? Organized Crime and the State in Brazil and Mexico". Journal of Politics in Latin America 2/2009: 3-29.

4. Brennan-Galvin, Ellen (2002). "Crime and violence in an urbanizing world", Journal of International Affairs; Fall, 2002; 56, 1; ABI/ INFORM Global.

5. Colvin, Mark (2007). "Applying Differential Coercion and Social Support Theory to Prison Organizations: The Case of the Penitentiary of New Mexico". The Prison Journal 2007; 87; 367. DOI: 10.1177/0032885507304774

6. Cuadra, Sergio (2003). "Globalization and the capacity of violence to transform social spaces: Some Critical points of the Latin America Debate". Crime, Law and Social Change; Mar 2003; 39, 2; ABI/INFORM Global. Pp 163-173.

7. Danitz, Tiffany (1998). "The gangs behind bars"

8. http://findarticles.com/p/ articles/mi_m1571/is_n36_ v14/ai_21161641/

9. Davis, Diane E. (2006). "The age of insecurity: violence and social disorder in the new Latin America", Latin American Research Review; 2006; 41, 1; ABI/INFORM Global.

10. García Ramírez, Sergio. (2004). "Crimen y prisión en el nuevo milenio". Boletín Mexicano de Derecho Comparado, No. 110, 2004, pags. 547.595

11. Jütersonke, Oliver, Robert Muggah and Dennis Rodgers (2009). "Gangs, Urban Violence, and Security Interventions in Central America", Security Dialogue 2009; 40; 373.

12. Mehlum, Halvor, Karl Ove Moene \& Ragnar, Torvik (2002). "Plunder \& Protection Inc.", Journal of Peace Research 2002; 39; 447 DOI: $0.1177 / 0022343302039004005$ 
13. Millett Richard y Thomas Shannon Stiles (2008), "Peace Without Security: Central America in the 21st Century", Whitehead Journal of Diplomacy and International Relations, VOL 9; NUMB 1, pages 31.42.

14. Richards, Stephen C., Greg Newbold, \& Jeffrey Ian Ross (2009). "Convict Criminology." 21st Century Criminology: A Reference Handbook. 2009. SAGE Publications. 9 Apr. 2010.

http://www.sage-ereference.com/ criminology/Article_n41.html.

15. Sousa Brandão, Thadeu (2008). "Organizações Criminosas no Brasil: uma Análise a partir Dateoria das Elites e da Teoria da Ação Coletiva". Revista Eletrônica Inter-Legere Número 03 (Jul/Dez 2008).

\section{Periódicos y páginas web}

1. Dirección General de Centros Penales http://www.seguridad. gob.sv/index.php?option=com_co ntent\&view $=$ article\&id=80\& $\mathrm{tem}$ id $=140$

2. Discurso del Sr. Presidente de la República Mauricio Funes Cartagena, en Cadena Nacional de Radio y Televisión, 23 de junio 2010, http://www.presidencia.gob. sv/discurso/2010/06/disc2301. php

3. Diario de Hoy (2008), "Han decomisado 794 celulares y 618 chips. Hampa sigue operando tras las rejas". 17 agosto 2008.

4. El Diario de Hoy (2010a), "115 celulares iban ocultos en comida", 8 de junio 2010.

5. El Diario de Hoy (2010b), "Deficiente control para frenar tráfico de celulares en penales", 10 de mayo $2010 \mathrm{http}: / / \mathrm{www}$.elsalvador. $\mathrm{com} / \mathrm{mwedh} /$ nota/nota_completa asp? idCat $=6358 \&$ idArt $=4777043$.

6. El Diario de Hoy (2010c), "Funes culpa a medios del clima de impunidad", 30 de mayo 2010. http://www.elsalvador.com/ mwedh/nota/nota_completaasp?i dCat $=6351$ \&idArt $=4833133$

7. El Diario de Hoy (2010d), "Maras reciben \$9.6 MIls. por extorsión", 10 junio 2010.

8. Diario de Hoy (2010e), "A 66 suben asesinatos de empleados de transporte público", 2 de junio 2010.

9. El Faro (2010), 2009 el año más violento desde 1992. http:// www.elfaro.net/es/201001/ noticias/820/

10. Fundación Nacional para el Desarrollo (2005), "Desempeño económico y del mercado de trabajo de El Salvador 2004/2005", Global Policy Network.

http://noticias.terra.es/2010/ mundo/0102/actualidad/el. salvador-registro-4365-homicidios. en-2009-la-cifra-mas-alta-en-diezanos.asp $\underline{x}$

11. La Prensa Gráfica (2009), "Extorsiones desde cárceles aumentan más de 100\%". http:// www.laprensagrafica.com/ el-salvador/judicial/52657. -extorsiones-desde-carceles. aumentan-mas-de-100.html 12 agosto 2009.

12. La Prensa Gráfica (2010a), "Cárceles dejan de recibir Reos", 13 julio 2010.

13. La Prensa Gráfica (2010b). "Deuda originada en centros penales," 03 junio 2010. http:// www.laprensagrafica.com/el. salvador/judicial/122158-deuda. originada-en-centros-penales.html.

14. La Prensa Gráfica (2010c). "Ingresan a cárceles \$8.4 millones por extorsiones", 09 de enero 2010.

15. La Prensa Gráfica (2010d). "Reos dirigían red de extorsión El SalvadorEUA", 10 de junio de 2010. 
El Crimen Organizado en las Cárceles:
Las Extorsiones desde los Centros Penales en El Salvador (2008-2009)

16. López, Jaime (2010), “EE.UU. ofrece un millón para el Centro de Intervención", El Diario de Hoy, 12 de enero de 2010.

17. Mance, Henry (2009). "Dentro de las cárceles de los Maras" http: / / www.elespectador. com/impreso/internacional/ articuloimpreso150753-dentro. de-carceles-de-los-maras $14 \mathrm{Jul}$ 2009.

18. Membreño, Tania. (2010) "Extorsiones desde penales aumentan 600\%, La Prensa Gráfica, 18 de enero.
19. Revista Summa (2010). "16\% de empleados privados en El Salvador gana menos que el salario mínimo",15 junio 2010. 